University of South Florida

DIGITAL COMMONS

@ UNIVERSITY OF SOUTH FLORIDA
Digital Commons @ University of South Florida

$3-2003$

\title{
Safer Stops for Vulnerable Customers
}

CUTR

Follow this and additional works at: https://digitalcommons.usf.edu/cutr_nctr

\section{Scholar Commons Citation}

CUTR, "Safer Stops for Vulnerable Customers" (2003). Research Reports. 246.

https://digitalcommons.usf.edu/cutr_nctr/246

This Technical Report is brought to you for free and open access by the National Center for Transit Research (NCTR) Archive (2000-2020) at Digital Commons @ University of South Florida. It has been accepted for inclusion in Research Reports by an authorized administrator of Digital Commons @ University of South Florida. For more information, please contact digitalcommons@usf.edu. 


\section{Safer Stops for Vulnerable Customers}

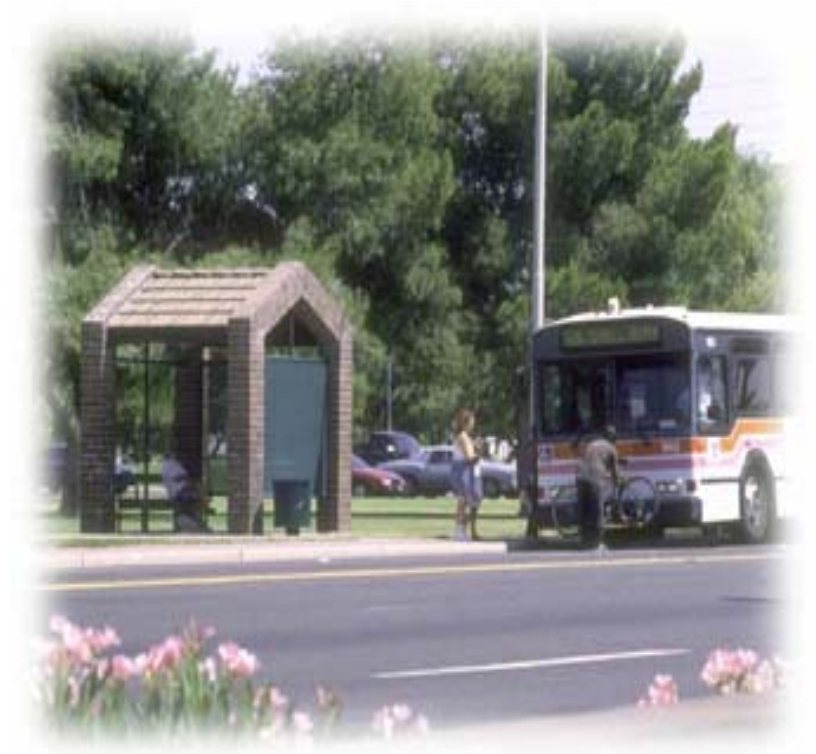

State of Florida Department of Transportation

Public Transit Office

605 Suwannee Street

Tallahassee, FL 32399-0450

(850) 414-4500

Project Director:

Joel Volinski, Director

National Center for Transit Research

Principal Investigator:

Lisa E. Tucker, Research Associate

March 2003 


\begin{tabular}{|c|c|c|c|}
\hline $\begin{array}{l}\text { 1. Report No. } \\
\text { NCTR-473-13 }\end{array}$ & 2. Government Accession No. & \multicolumn{2}{|c|}{ 3. Recipient's Catalog No. } \\
\hline \multicolumn{2}{|l|}{ 4. Title and Subtitle } & \multicolumn{2}{|c|}{$\begin{array}{l}\text { 5. Report Date } \\
\text { March } 2003\end{array}$} \\
\hline \multicolumn{2}{|c|}{ Safer Stops for Vulnerable Customers } & \multicolumn{2}{|c|}{ 6. Performing Organization Code } \\
\hline \multicolumn{2}{|l|}{$\begin{array}{l}\text { 7. Author(s) } \\
\text { Tucker, Lisa E. }\end{array}$} & \multicolumn{2}{|c|}{ 8. Performing Organization Report No. } \\
\hline \multirow{2}{*}{\multicolumn{2}{|c|}{$\begin{array}{l}\text { 9. Performing Organization Name and Address } \\
\text { National Center For Transit Research (NCTR) } \\
\text { University of South Florida CUT } 100 \\
4202 \text { East Fowler Avenue, Tampa, FL } 33620\end{array}$}} & \multicolumn{2}{|l|}{ 10. Work Unit No. } \\
\hline & & \multicolumn{2}{|c|}{$\begin{array}{l}\text { 11. Contract or Grant No. } \\
\text { DTRS98-G-00329 }\end{array}$} \\
\hline \multirow{2}{*}{\multicolumn{2}{|c|}{$\begin{array}{l}\text { 12. Sponsoring Agency Name and Address } \\
\text { Office of Research and Special Programs (RSPA) } \\
\text { U.S. Department of Transportation, Washington, D.C. } 20590 \\
\text { Florida Department of Transportation } \\
605 \text { Suwannee Street, MS 26, Tallahassee, FL } 32399\end{array}$}} & \multicolumn{2}{|c|}{ 13. Type of Report and Period Covered } \\
\hline & & \multicolumn{2}{|c|}{ 14. Sponsoring Agency Code } \\
\hline \multicolumn{4}{|c|}{$\begin{array}{l}\text { 15. Supplementary Notes } \\
\text { Supported by a Grant from the USDOT Research and Special Programs Administration, and the } \\
\text { Florida Department of Transportation }\end{array}$} \\
\hline \multicolumn{4}{|c|}{$\begin{array}{l}\text { 16. Abstract } \\
\text { As transit agencies continue to seek innovative and effective means of increasing ridership anc } \\
\text { improving the image of public transportation, the bus stop must be acknowledged as part of the } \\
\text { overall transit environment. Factors such as the location, design, maintenance, and genera } \\
\text { appearance of bus stops greatly affect the public's perception, and often the reality of a stop's } \\
\text { safety and security. This synthesis report presents a brief synopsis of the current literature anc } \\
\text { technologies being used in the development of safer and more secure bus stops. While the focus } \\
\text { is most specifically with regard to vulnerable populations-women, children, senior citizens, anc } \\
\text { the disabled-improvements related to the safety and security of bus stops may be of benefit to al } \\
\text { transit users, potential users, the community at large, and the transit industry in general. }\end{array}$} \\
\hline $\begin{array}{l}\text { 17. Key Words } \\
\text { Public transit, bus stops, safety, } \\
\text { security, transit customers }\end{array}$ & $\begin{array}{l}\text { 18. Distribution Statement } \\
\text { Available to the } p \\
\text { Information Servi } \\
\text { VA 22161, (703) } \\
\text { the NCTR web si }\end{array}$ & $\begin{array}{l}\text { the Natio } \\
85 \text { Port R } \\
\text { tp://www.n } \\
\text { w. nctr.us }\end{array}$ & $\begin{array}{l}\text { ical } \\
\text { ind through }\end{array}$ \\
\hline $\begin{array}{l}\text { 19. Security Classif. (of this report) } \\
\text { Unclassified }\end{array}$ & $\begin{array}{l}\text { 20. Security Classif. (of this page) } \\
\text { Unclassified }\end{array}$ & $\begin{array}{l}\text { 21. No. of pages } \\
87\end{array}$ & 22. Price \\
\hline
\end{tabular}




\section{Executive Summary}

The safety and security of public bus stops are critical considerations for patrons, potential users, transit agencies, and the communities they serve. As transit agencies continue to seek innovative and effective means of increasing ridership and improving the image of public transportation, the bus stop must be acknowledged as part of the overall transit environment. Factors such as the location, design, maintenance, and general appearance of bus stops greatly affect the public's perception, and often the reality of a stop's safety and security.

Some transit customers are generally considered to be more vulnerable in terms of their safety and security at bus stops. Women, children, senior citizens, and the disabled often have additional or different needs and preferences than the population at large. Because these groups constitute a large portion of transit ridership, it is important to address their concerns and explore available options in mitigating the problems associated with the safety and security of these vulnerable populations.

Senior citizens and women typically have a greater fear for their own personal security, and for those with children that caution extends to their children as well. Situations causing the most anxiety tend to be those in which passengers are alone at a bus stop, waiting in a deserted or dark area, or waiting in crime-ridden neighborhoods. For customers with physical disabilities, access to the bus stop and safety are particularly important.

The environmental attributes of the area surrounding a bus stop also contribute to the safety and security of waiting passengers. Aspects of the built environment as well as the location and design of the bus stop may greatly affect both customers' and criminals' perceptions of the security of a particular bus stop. Certain land use characteristics such as liquor stores, bars, check-cashing establishments, and pawn shops are considered to be "negative" land uses, detrimental to the safety and security of bus stops. In addition, factors such as 
graffiti and litter around the stop may encourage anti-social behaviors and contribute to the perception that no one monitors or cares about the area.

Various strategies have been undertaken in an attempt to provide safer and more secure bus stops for transit customers. Careful examination and planning of the location and design of bus stops are paramount to creating a safe and secure transit environment. Street furniture such as shelters, benches, garbage receptacles, vending machines, and appropriate signage may convey a semblance of ownership and contribute to customers' perceptions of a positive transit experience, provided the stop is well maintained. Adequate lighting of the bus stop area is an important safety and security feature to patrons, particularly among those customers considered to be more vulnerable.

In addition to theoretical and practical approaches, several technologies have been developed specifically to enhance the safety and security of bus stops. Real-time information systems using GPS and AVL, solar-powered lighting, auditory signage and other directional systems, and "smart" shelters offer many features that are often adaptable to individual agency needs and budgets.

Given the nature of public transportation, it is most logical that there be public involvement in the planning of transportation services, including the location, design, features, and maintenance of bus stops. Collaboration provides a vehicle for dialogue and service improvements between transit agencies and the communities they serve. Several Adopt-A-Stop programs have been implemented throughout the country, through which volunteers agree to monitor the upkeep and cleanliness of their "adopted" bus stop. Such programs provide a sense of ownership and interest within the community and the volunteers' activities improve the physical appearance of stops in general, thereby improving the safety and security of bus stops for all transit customers. 


\section{Table of Contents}

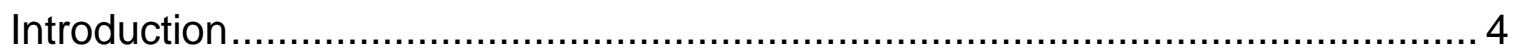

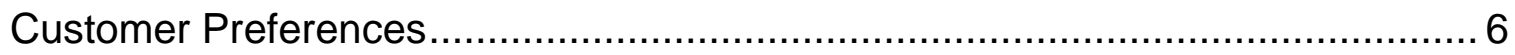

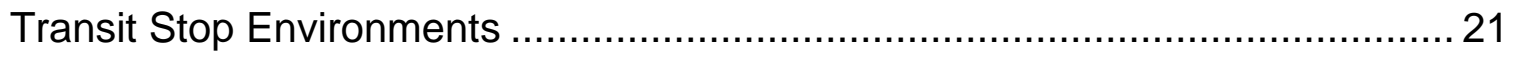

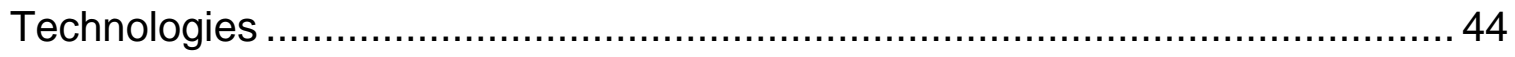

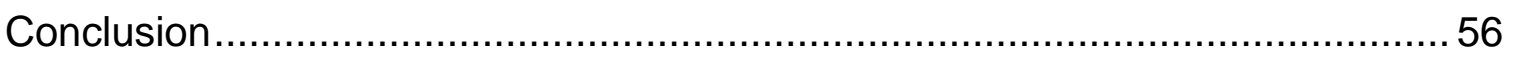

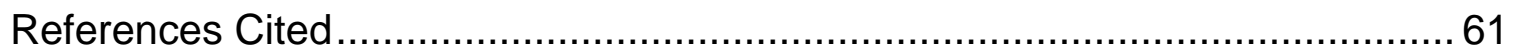

Appendix A

Arlington County Bus Stop Assessment Form .. Error! Bookmark not defined.

Appendix B

Delaware Department of Transportation Bus Stop and Passenger Facilities

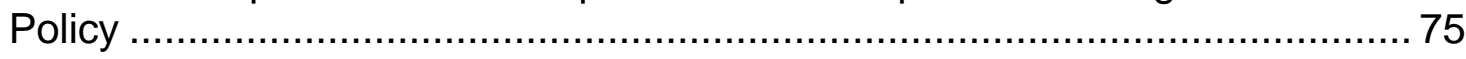

Appendix C

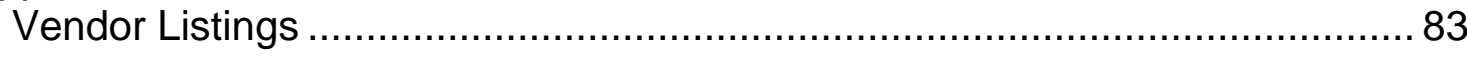

\section{List of Figures}

Figure 1: The Process of NextBus Technology (NextBus Information Systems,

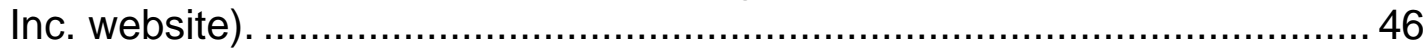

Figure 2: Features of the Smart Shelter (Daytech Manufacturing, Inc. website). 48

Figure 3: Three Yellow Blind Sign Strips Denoting a Bus Stop (Blind Signs, Inc. website).

Figure 4: Three Yellow Blind Sign Strips Indicating Where to Board the Bus (Blind Signs, Inc. website).

Figure 5: Four Red Blind Sign Strips Indicating Crosswalk and Direction (Blind Signs, Inc. website). 


\section{Introduction}

Safety and security at public bus stops are critical considerations for patrons, potential users, transit agencies, and the communities they serve. As transit agencies continue to seek innovative and effective means of increasing ridership and improving the image of public transportation, the bus stop must be acknowledged as an important part of the overall transit environment. Whether the location, design, and maintenance of stops fall under the jurisdiction of the local government, citizen groups, private companies, or the transit agency itself, users and non-users alike perceive the bus stop to be part of the transit system, and therefore part of their experience in using transit.

In addition to its practical function as a location of waiting for, boarding, and alighting the bus, the transit stop may also serve unintentionally as a public relations liaison of sorts within the community. The physical condition of the stop and its amenities contribute to the image of the local transit agency as well as the safety and security of public transportation in general. The environmental attributes surrounding the bus stop and its location, design, and appearance all factor into the image of safety and security in the collective mind of the public. The perception of personal safety and security at bus stops may affect travelers' decisions of what routes or stops to use, or at least their confidence in using those routes or stops. Of further import, this perception could quite possibly affect the decision of whether to use transit at all.

Some populations are generally considered to be more vulnerable than are others with regard to issues of safety and personal security in public areas. Women, children, the disabled, and senior citizens frequently have separate or additional needs and preferences in relation to safety and security, and there is often particular concern regarding bus transit stops. These considerations are paramount and may affect access to jobs, childcare services, social networks, the bus stop itself, overall quality of life, and travel behaviors. 
The purpose of this study is to present a brief synopsis of the current literature and technologies being used in the development of safer and more secure bus stops. While the focus is most specifically with regard to vulnerable populations, improvements related to the safety and security of bus stops may be of benefit to all transit users, potential users, the community at large, and the transit industry in general.

A literature search was conducted using the Transportation Research Board TRIS database, and the internet was searched for other relevant sources. In order to present the most current information, resources reviewed for this document were limited to those produced in the last five years (with the exception of one significant TCRP report). Transit agency personnel were also contacted to provide their opinions on select operational topics and technologies.

The first section, Customer Preferences, reviews the perceptions and preferences of transit users as well as non-users, particularly as they relate to safety and security at the bus stop. The next section, Transit Stop Environments, considers the bus stop within the broader context of its surrounding environment. Location, environmental attributes, design, access, and street furniture are addressed. The third section, Technologies, reviews some of the latest advancements in technologies designed to make transit, particularly bus stops, safer and more secure for passengers. Finally, the Conclusion includes a brief discussion regarding the opportunities and benefits of collaboration in the making of safer and more secure bus stops for vulnerable customers. 


\section{Customer Preferences}

Steadily increasing public involvement in transit planning and community design has led researchers and planners to seek in-depth and often innovative means of determining what the public prefers in relation to their transportation options. The industry is gaining a better understanding of how the public perceives bus transit and what peoples' expectations are when using public transportation. Studies exploring the preferences and perceptions related to personal safety and security have focused much of their efforts on the surrounding environment of the bus stop and the design of the stop itself. Women, senior citizens and the disabled are often referenced as having particular concerns regarding their safety and security at bus stops.

According to Ewing (2000), designers all too often impose their own taste over that of the user or client, or at the least they make unfounded assumptions about user preferences in design. Visual preference surveys are growing in popularity in physical planning projects utilizing intensive public involvement, and are one means of determining those design elements most desired by the public. Ewing used this type of survey to query transit users about transit-oriented design and the preferred characteristics of bus stops.

The author provides a brief explanation of the use of visual preference surveys and the methodology employed in a particular study conducted in Sarasota, Florida. Participants included users, non-users, and professionals, and collectively they were shown slides of bus stops, downtown transit centers, and transfer facilities. Ewing admits anticipating some variability in responses based on participant status as a user, non-user, or professional; however, the results of the survey did not coincide with that initial expectation. In general, regardless of the participants' status, those features most positively affecting the preference for a particular bus stop included (in order of declining significance): 
- shelter;

- bench (without a shelter);

- trees or an overhang shading the bus stop;

- vertical curb at the bus stop; and,

- trees along the street leading to the bus stop.

The most preferred bus stops were then rated by participants during the survey. Ewing reports the following variables had the most positive effect (in order of declining significance):

- shelter;

- trees along the street leading to the bus stop;

- setback of the bus stop from the street edge;

- location of the stop at an intersection; and,

- vertical curb at the bus stop.

Ewing also reports that the following variables significantly affected both bus stop preference and rating:

- shelter;

- trees along the street leading to the stop;

- vertical curb at the stop;

- setback of the stop from the street edge; and,

- continuous sidewalk leading to the stop.

Ewing makes no specific mention regarding the preferences of more vulnerable populations or their participation in this research. He stresses that the study used a small sample and is exploratory. The author's interest lies in the application of the visual preferences survey method rather than the results of this particular study. However, it is of note that shelters were consistently ranked high in bus stop choice among users (2.63 on a 5-point scale, 5 being highest), non-users (3.01), and professionals (3.18), for an average participant rating of 2.79. Bus stop benches with no shelter were a distant second in choice preferences with a combined participant rating of 1.35. 
Ewing claims the results of this study conform to what is generally known regarding transit-oriented and urban design, defensible space, and environmental preferences. He asserts that despite this, visual preference surveys may assist transit planners in determining the best transit stop locations and separating the most important from the many other less important features of transit-oriented design, thereby maximizing typically limited financial resources. Such a method may hold great potential in determining the needs and preferences of women, children, senior citizens, and the disabled.

Lusk (2002) used visual preference surveys in an assessment of bus and bus stop design characteristics that contribute to the perception of crime. While the majority of Lusk's report is devoted to the design and appearance of buses, fifteen focus groups of 168 diverse participants in Detroit and Ann Arbor, Michigan; Burlington, Vermont; and Washington, D.C. were shown 70 slides which included 15 photographs of varying bus stop shelter designs.

Lusk reports that the following qualities were mentioned positively during the group sessions regarding participants' favored bus stop shelter:

- brick/masonry construction;

- open space;

- no bushes;

- architecture;

- bus stop location name on the shelter;

- some preferred the glass back wall;

- some prefer an open back, while others prefer a U-shaped design for protection; and,

- if a U-shaped shelter, an open front is preferred; other preferences include a shelter with an open front and open back or one with no sides.

The stop least preferred by study participants was one with no side and rear walls to the shelter, giving the impression of vulnerability to sidewalk traffic behind the shelter. Blind alley entranceways near the stop were also mentioned as causing feelings of insecurity. According to Lusk, a bus stop must "look like a 
bus stop." In order to feel in control and confident, people must feel they are in control of their environment and of themselves. The author recommends a shelter resembling a safe building or home, a clearly visible location/stop name, the provision of a bus schedule, perhaps a map, the stop should be well lit, and if there is a U-shaped opening, it should face the street rather than the sidewalk. Participants also reported a preference for clear glass walls all the way around with no advertising; not too much or too dense vegetation around the stop; and a shelter that is not too artistic. The stop should be well-maintained and clean; otherwise there is the suggestion of criminal activity. The author also notes that women may have needs and perceptions related to personal security at the bus stop that differ from those of men. Women are not as strong as are men, they may have to provide care for small children, and are therefore often unable to "fight or flee" (Lusk 2002:2) in the event of a risk to their personal security.

Stephens et al. (1999) consider obtaining information related to customer preferences to be difficult and a primary obstacle in the creation of a literature devoted to the safety issues of transit's "special populations." This category includes those from outside the United States who must familiarize themselves with the transit infrastructure, as well as 32 million senior citizens, 24 million people with some form of disability, and 56 million children under the driving age. Although the authors include school bus riders in this latter figure they refer the reader to other sources for information on school bus safety. They do note that transit and paratransit are often used to supplement school bus transportation, particularly for students with special needs or those in rural areas. The authors consider it problematic that there are no uniform reporting standards providing data related to the transit safety problems faced by these groups, thereby making it difficult to address their needs and preferences.

In an effort to add to the knowledge base on this topic, Stephens et al. obtained information from transit users from the special populations and professionals who work with these groups, transit agencies, and two focus groups-one comprised of visually-impaired participants, and one with senior citizens. Based on their own review of the literature, the analysis of bus transit incident data, and input from the participants in this study, the authors found there to be relatively few 
safety problems during travel on transit vehicles. The potential danger for these users was found to be in their travel to and from the transit vehicles.

In general, those with ambulatory disabilities and seniors were the most concerned with safety using public transit; however, those who use transit relatively frequently were found to be less concerned than were others. Stephens et al. attribute this to the development of adaptive strategies for dealing with perceived or potential hazards. While none of the groups judged entering or exiting transit vehicles, bus stops, or transit terminals to be generally unsafe, a majority of the groups considered crossing streets to access transit areas a dangerous activity.

According to Stephens et al., the most pervasive safety problems identified in this study included:

- street crossings away from intersections, creating potential danger in getting to transit vehicles;

- crossing streets at complex signalized intersections, particularly for the visually-impaired and older populations;

- slipping or falling when entering buses, especially when vehicles and curbs are not aligned;

- falling within transit vehicles during rapid acceleration or braking;

- sidewalks or paths cluttered or having street furniture not arranged systematically;

- improper cues as to where pedestrians are, causing individual's disorientation or getting lost;

- steep inclines and steps may adversely affect many with ambulatory disabilities; and,

- lack of good quality auditory clues at crossings and on transit vehicles, particularly hazardous for visually-impaired persons.

Although the authors state their purpose was not to generate recommendations for the improvement of identified safety problems, they did query participants as to the benefit offered by commonly suggested or implemented solutions. Signal 
timing at intersections was judged to be a beneficial safety measure. Audible signals also received a positive response, although in discussion the authors determined there may be design problems such as the location of intersection buttons for activation and the directionality of the speakers. Most groups considered the placement of street furniture where transit users must walk to be a detriment to safety.

Further investigation into customer preferences regarding safety and security enhancements was conducted by Reed et al. (2000). In this study the authors focus upon the measuring and improvement of customer perceptions of safety and security in relation to transit use. The 74 transit agencies in Michigan were classified as serving a metro area, large urban, medium urban, or all other, which were primarily systems in small urban or rural areas. Surveys were conducted among riders of each of these systems, and the authors received 761 completed questionnaires, which comprised the sample for this study.

Passengers generally claimed to feel safe when using public transit but feel less safe when traveling after dark, and those traveling on smaller systems feel somewhat safer than do those using larger systems. In general, women reported feeling less safe than did men, and they were found to be more appreciative of security enhancements.

Reed et al. asked participants to rate the following potential security enhancements:

- more police;

- more driver safety training;

- increased lighting at bus stops;

- see-through bus shelters;

- emergency telephones at bus stops;

- video cameras on transit buses; and,

- driver-operated emergency alarms. 
The installation of emergency telephones at bus stops was the most highly rated enhancement among participants from all strata of systems, with the exception of the medium urban stratum which ranked it second to increased lighting at stops. Increased lighting was rated the second highest enhancement among all strata except the metro area, which rated more police the second highest. The metro area stratum ranked see-through bus shelters as third highest, and women across the strata favored see-through bus shelters, more driver safety training, and increased lighting at bus stops. These results indicate to the authors that transit patrons, particularly women, feel less secure waiting at stops than while riding on the bus.

Reed et al. suggest that transit service improvements may relate directly to a passenger's safety at the bus stop, and that participant responses exhibited this fact. Respondents from the metro area stratum claimed to be dissatisfied with printed schedules, signs, and other information at bus stops. In addition, respondents from all strata were dissatisfied with the limited availability of weekend and night service. The authors assert that waiting time is an important safety consideration in many areas, and the longer a passenger's wait time, the longer that passenger is exposed to potential crime. Limited availability of weekend and night service may also contribute to this hazard if customers are forced to travel further distances to a stop, particularly after dark. Reed et al. stress the importance of bus frequency and timeliness.

Based on the results of this study the authors make suggestions for security improvements at bus stops to transit agencies, the Michigan Department of Transportation, and the State Legislature. Those recommendations specifically for the transit agencies, with recognition that the appropriateness of each is agency-specific include:

- gather and analyze bus stop-level crime data to direct the policing of stops; identify stops that need improved lighting or other such enhancements; relocate bus stops away from high crime areas; and direct other safety enhancements; 
- collaborate with police and security personnel to increase presence at stops and major transit transfer centers, particularly the most crime-prone stops;

- emergency telephones at bus stops;

- increase lighting at bus stops that are insufficiently lit;

- improve signage at stops without adequate information;

- relocate bus stops from areas such as dark alleys and abandoned buildings that may expose passengers to undue crime risk;

- install onboard or bus stop video surveillance for routes in high-crime areas; although the authors do note that customers may not necessarily feel more secure and the cameras may displace the crime to areas without cameras, requiring police attention elsewhere; and,

- provide more frequent service and better schedule adherence to minimize passenger wait times and exposure to potential crime.

Reed et al. suggest that the Michigan Department of Transportation should encourage and assist transit agencies in the implementation of safety and security enhancements. Further, they recommend that design guidelines be developed for bus stop shelters, lighting, and signage. With regard to legislation, the authors recommend that the State Legislature increase the penalties for crimes against bus drivers and passengers. They contend such legislation must include passengers who are victimized while waiting at a bus stop because these areas can be considered crime locations.

Wallace et al. (1999) found similar results in an earlier study on transit safety and security enhancements that had already been made in Ann Arbor, Michigan. Although specifically focused on improvements made at transit centers, the authors' findings regarding increased lighting and police presence mirror that of Reed et al. (2000), and can generally be extended to individual bus stops as well. Furthermore, Wallace et al. also found that women felt less safe overall than did men, and that they were more likely to notice and to appreciate measures taken to improve safety and security. The authors used survey data collected from fixed-route users during 1997 and 1998 to assess customer responses to safety 
and security features implemented by the Ann Arbor Transportation Authority (AATA) at transit centers.

Prior to the first period of survey data collection, the AATA had implemented the following programs and equipment:

- comprehensive new driver and refresher training in all aspects of safety and security;

- formal review and evaluation of accidents and incidents;

- security cameras at transit centers;

- enhanced security lighting at transit centers; and,

- police/security mini-stations.

Other enhancements were made prior to the second data collection period under the AATA's Advanced Operating System (AOS), an integrated communication, operation, and maintenance system. Although the authors provide no specifics as to what these improvements were, their discussion of the survey results indicates that emergency telephones and on-board video cameras were some of the additional measures taken.

AATA also instructs all drivers and other personnel to file a written incident report for any occurrence that could have resulted in an injury and for all incidents involving any kind of dispute or altercation. Such reporting goes beyond those statistics in the National Transit Database, and advances the frequent call for the development of reporting standards and guidelines. Wallace et al. acknowledge that although such measures and evaluations may contribute to lowering the frequency and severity of occurrences, the perception of safety and security by transit users, non-users, and employees is crucial. Their perceptions may or may not reflect the actual occurrence of incidents, and one highly publicized crime may significantly affect public perceptions. The authors note that the cleanliness of transit centers may also affect passengers' perceptions of safety and security. 
Of the safety and security enhancements implemented at the transit centers, the most noticeable to passengers during the 1998 survey were security cameras, followed by more police presence, increased lighting, and finally, emergency telephones. Those improvements resulting in the increased perception of security, however, were more police presence and increased lighting. Although still creating a positive effect, emergency telephones and the presence of video cameras had a smaller impact on passenger feelings of security. Wallace et al. note these findings are in contrast to results of the 1997 survey in which passengers indicated those enhancements that would make them feel more secure were increased lighting and emergency telephones, with more police and video monitoring scoring much lower. The authors suggest it is the visibility of police compared to telephones that may be responsible for this discrepancy.

Wallace et al. conclude by stating that based on the results of this study, in order to affect passengers' perceptions, safety and security measures must be visible and noticed. The authors contend, however, that many passengers' perceptions are directly related to the characteristics of the passengers themselves rather than the transit service. This is highlighted by the fact that women generally feel less safe than do men, yet the authors note that in this study women were more observant of safety and security enhancements, indicating that as a group they gain more peace of mind from such improvements.

Nsour (1999) also addresses the concern expressed by women in relation to their feelings of safety and security. In a study involving 381 transit users, 531 non-users, and 25 transit agencies, Nsour found that security ranked fourth among all non-users as their reason for not using the bus, and safety only "accounted for a small portion of responses" (8). In response to a direct question as to whether issues of safety and security are preventing them from using bus transit, 27.9 percent of female respondents answered positively compared to 12.3 percent of male respondents. The author also found that regardless of sex the overall perception of risks related to safety and security is higher among nonusers (17 percent) than users (six percent).

Like Reed et al. (2000) Nsour asserts that longer wait times are directly related to passenger feelings of insecurity, yet notes that in this study wait times were not 
recognized by any of the participating transit agencies as a security factor. However, punctuality of buses and the uncertainty of their arrival were found to be significant to transit users in terms of personal security. Nsour states that many users suggested increasing the frequency of buses as a means of increasing security, but the author does not address the feasibility of doing so.

Further evidence of women's feelings of vulnerability is provided by Bell (1998). This author discusses women's experience and perception in relation to community safety in general, and discusses public transportation as an issue within that topic. Bell states that women have higher use levels of the public realm than do men, although they utilize a narrower geographic range. They are more likely to frequent shopping centers, parks, pathways, residential areas, and public transit areas, all of which are "vulnerable to crime or incivility" (4). Bell reports that women feel less secure using public transportation than in other areas of the general community, but that crime statistics show they are actually at a lower risk of crime.

Bell claims that women's experience with regard to safety in urban areas is different than that of men. Women's fear of violence and crime often affects their use of urban areas and the public realm. Older women in particular are more likely to alter their lifestyles and routines in response to their fear of crime than are men, thereby affecting their quality of life. Specifically, Bell states that women are most fearful of the following situations:

- any mode of transportation other than the car;

- going out at night;

- walking to the nearest shops;

- use of public transportation, most particularly train travel at night;

- use of a public telephone;

- walking to a friend's house;

- walking through a park or walking home from local destinations such as movie theaters, restaurants, and bars;

- either end of a journey involving public transportation, specifically waiting at a bus stop or walking from a station to a parked car; 
- use of city center parking lots, particularly at night and if a multi-story facility;

- driving alone at night; and,

- open spaces such as parks and the countryside and pathways such as alleyways and underpasses.

According to Bell, the level of activity in an area and its degree of enclosure also affect women's perception of security. Women are generally fearful of deserted spaces which lead them to feel vulnerable to attack by a stranger because there are no other people in the area to deter or prevent the attack. With regard to more enclosed spaces, women are fearful because of the limited number of exits and the potential for attackers to hide outside the view of others.

Bell argues that transit stops are particularly vulnerable to criminal activity and there is a great need to promote safety and security in these areas. Specifically, the author recommends that stops be located, designed, and managed to ensure the security of transit users. This would mean locating bus stops in areas of high activity, with surveillance from passers-by, and with good maintenance and lighting. Bell also mentions Crime Preventions Through Environmental Design (CPTED) and other design or planning strategies as means of improving the safety and security of public transportation. These topics will be discussed further in the following section of this report.

With specific regard to the transportation needs and preferences of senior citizens, Ritter et al. (2002) conducted a nation-wide survey of 2,422 adults age 50 and above. The authors surveyed respondents about a variety of transportation-related topics such as their mode use, personal mobility, social interaction, and levels of satisfaction with respect to each. Participants were also asked about their problems with various transportation modes. Regardless of the availability of public transportation in their respective locations, participants were asked to determine whether the following ten situations presented them with a large problem, a small problem, or no problem. 
- crime;

- unavailable destinations;

- takes time;

- accessibility;

- difficult transfers;

- stations and vehicles not maintained;

- too expensive;

- service information;

- difficulty boarding; and,

- getting a seat.

Of those situations most relevant to bus stops, crime was considered a large problem by 16 percent of respondents and a small problem by 23 percent. Unavailable destinations were found to be a large problem for 24 percent and a small problem for 14 percent of survey participants. Although the authors do not define the category takes time specifically, waiting time is often considered a security issue at bus stops simply due to the potential of exposure to dangerous situations. Sixteen percent of survey respondents rated takes time to be a large problem, while 22 percent consider it a small problem. With regard to accessibility, 20 percent considered it to be a large problem and it was rated to be at least a small problem by 11 percent of participants. Difficult transfers was rated a large problem by 13 percent of respondents and a small problem by 15 percent. Regarding stations and vehicles not being maintained, 11 percent rated this a large problem, while 14 percent considered it to be a small problem. Seven percent of respondents considered service information to be a large problem and nine percent of survey participants considered it a small problem. Difficulty boarding may also relate to bus stops, particularly in their design, and four percent of respondents rated this a large problem and nine percent considered it to be a small problem.

When the results are examined according to age categories, difficulty boarding represented a large problem for a higher percentage of respondents age 75 and older (11 percent) than it did for respondents age 50 to 74 (four percent). The authors also assert that the health and disability status (HDS) and driving status 
of respondents in this older age category affect their perception of the magnitude of public transportation problems. Those age 75 and older with poor HDS were twice as likely to indicate large problems as were those in the same age group with excellent HDS. Non-drivers in this age group generally have the same responses as those with poor HDS. Ritter et al. also address problems with other modes for seniors and discuss the implications of transportation policy for older persons.

Coughlin (2001) explored the transportation perceptions and preferences of senior citizens age 75 and older through three focus groups and 17 in-person interviews. All participants identified public transportation as a less attractive option than driving or being driven, primarily due to concerns for personal safety and security. The author notes, however, that participants identified transit positively as offering some level of independence in that they did not have to ask others for a ride.

Participants expressed general concern about going out at night, but the author reports this concern was particularly strong with regard to using public transportation. Some participants asserted that concerns for their personal safety and security at night meant public transportation was not a realistic mode when making trips in the evening for entertainment purposes.

Although not specifically queried about their needs and preferences at bus stops, Coughlin's results indicate a general fear of public transit among the senior participants. The author quotes one participant as saying she was afraid of "gangs and young hoods" that she may encounter while using transit (11). According to Coughlin, participants agreed that transit has "inherent negative attributes," the two primary factors being the time spent waiting and waiting in bad weather, both directly related to bus stops. The author concludes with a discussion on the implications for policy-making based on the findings in the study.

The needs and preferences of transit customers as well as potential customers are integral to understanding how to make bus stops safer and more secure, particularly for vulnerable populations such as women, children, senior citizens, 
and those with disabilities. The literature on this topic reveals that women and older people have somewhat similar concerns related to fear of crime and the security of the surrounding environment of bus stops. The perceptions of these frequent patrons are of great interest to transit agencies seeking to increase their ridership levels while maximizing limited funding. Bus stops that are safe and secure, both in appearance and in actuality, serve to promote a positive image of public transportation as well as that of the individual transit agency. 


\section{Transit Stop Environments}

As previously mentioned, both transit users and non-users tend to consider bus stops to be part of the overall transit environment. This transit environment includes more than the physical spot where the bus actually stops. Access to the bus stop and the area immediately surrounding the stop are generally thought to be part of the transit environment and these factors should be taken into consideration in the location and design of bus stops. Street furniture is often a factor in the safety and security of bus stops and contributes to the image of the transit environment. Furthermore, the maintenance of clean, safe, and secure bus stops and their surrounding environments greatly affects the perception of safety and security, as well as the actuality of these factors in the transit environment. Transit agencies, community groups, and departments of transportation are increasingly employing innovative strategies to improve the safety and security of transit stop environments. Continuing innovation in transit services is necessary if everyday services are to be available to the driving as well as the non-driving public. According to the American Public Transportation Association (APTA) more senior citizens, young mothers, children, and people with disabilities could access transit if system and community designs were improved. For example, approximately one in five older non-drivers could access fixed-route bus service if there were better sidewalks and resting places.

The location and design of bus stops are typically primary concerns among transit patrons. These factors may often present challenges to transit agencies attempting to satisfy their customers, provide safe and efficient service, work within budget, and maintain traffic flow. The Texas Transportation Institute was contracted through the Transit Cooperative Research Program (TCRP) to develop guidelines for the location and design of bus stops in a variety of operating environments. The research team conducted a literature review, surveys and interviews with those identified as stakeholders, and a review of the manuals of 28 transit agencies with regard to bus stop location and design. The guidelines developed from their review are presented in three sections, the "big picture," the street-side, and the curb-side. 
The research team defines safety as it relates to bus stops as "the freedom from danger and risk" (1996:5). Within a transit environment this includes one's relationship to buses and to general traffic, as well as the buses' relationship to other vehicles. For pedestrians, safety includes the distance of a bench to the flow of traffic on a busy street or being able to cross the street safely to access the bus stop. The return of the bus to the flow of traffic is also a safety concern. The authors note that pedestrians, bus passengers, buses, and private vehicles may all be involved in safety issues at or near a bus stop. With regard to security, the authors contend this relates to one's feeling of well-being in the transit environment and that it involves neighborhood residents, transit patrons, and bus drivers. Security may be affected by lighting at stops, potential hiding places surrounding bus stops, and the visibility of the bus stop from the street and nearby land uses.

Following the determination of ridership potential, the authors cite safety and avoiding the impediment of bus, car, or pedestrian flows as the most critical factors in bus stop location. They argue for the placement of stops in areas where common improvements, such as benches and shelters, may be made in the public right-of-way. On-site evaluation is required prior to the final decision regarding stop location. The following are safety factors to be considered in the placement of bus stops:

- passenger protection from passing traffic;

- access for people with disabilities;

- all-weather surface to step from/to the bus;

- proximity to passenger crosswalks and curb ramps;

- proximity to major trip generators;

- convenient passenger transfers to routes with nearby stops;

- proximity of stop for the same route in the opposite direction; and,

- street lighting. 
Within the discussion of placement considerations the authors present a comparative table of the advantages and disadvantages of far-side, near-side, and mid-block stops.

With regard to bus stop zone design types, the authors provide discussion and a comparative table of the types of stops: curb-side, bus bay, open bus bay, queue jumper bus bay, and nub. Several figures and photographs are provided illustrating the design and usage of each. The authors also discuss and provide illustrations of vehicle characteristics as well as roadway and intersection design.

According to the research team some general safety considerations in the design of bus stops include:

- the stop must be located so passengers may alight and board with reasonable safety;

- the stopped bus will affect sight distance for pedestrians using the parallel and transverse crosswalks at the intersection;

- the stopped bus will affect sight distance for parallel traffic and cross traffic; and,

- the bus affects the flow of traffic as it enters or leaves a stop.

Additional considerations include curb length, condition of the curb lane, and the curb height, all of which may affect passenger safety, particularly that of older or disabled people. The authors contend that if there are poor pavement conditions in the curb lane drivers will avoid it, stopping the bus away from the curb. The potential hazard lies in the increased height between the ground and first step of the bus as well as from vehicles such as bicycles moving between the curb and the bus. Street lighting is also mentioned as an important factor in the safety of bus stops because it allows bus drivers to see waiting patrons and it assists drivers of other vehicles in being able to see passengers boarding and alighting the bus.

Curb-side factors are also relevant to the safety and security of bus patrons. The authors argue that defined pedestrian access to and from the bus stop must be 
provided. Proper sidewalks should be constructed of impervious non-slip materials and should link the intersection or land use as directly as possible with the bus stop. They should be a minimum of three feet, preferably four to five feet wide, to accommodate wheelchairs, and wheelchair ramps should be available at all intersections. Discontinuous sidewalks from the intersection to the bus stop facilitate pedestrian access in those areas with limited or no sidewalks. Further, such features contribute to eliminating bus stop access through uneven grass or exposed soil, which may pose accessibility difficulties for seniors and the disabled, particularly in inclement weather. The authors note that when possible, sidewalks and bus stops should be coordinated with existing street lighting to provide some level of lighting and security for the area.

The authors devote a section to the discussion of ADA guidelines and how they relate to the location and design of transit stops. They also provide an illustration of the minimum dimensions of an accessible bus stop pad and shelter. Additionally, a list of resources and references related to ADA accessibility guidelines is included.

Often considered to be security improvements by transit patrons, bus stop shelters are discussed in terms of location, configuration and orientation, advertising, developer provision, and artistic and thematic designs. With regard to passenger and pedestrian safety the authors state that shelters with advertising make these factors a greater concern because advertising panels may restrict views into and out of the shelter. To mitigate this potential problem, the authors recommend that panels and kiosks be placed downstream of traffic flow.

Benches may also contribute to a safe waiting place for patrons, particularly senior citizens and those with disabilities. The authors provide the following guidelines with regard to the placement of benches at bus stops:

- avoid placing benches in completely exposed locations; coordinate with existing shade trees if possible; 
- coordinate placement locations with existing street lighting to increase visibility and security at the stop;

- avoid placing benches in undeveloped areas of the right-of-way; they should be located on a non-slip, properly drained, concrete pad;

- place benches away from driveways to increase passenger safety and comfort;

- at least two, and preferably four feet between the bench and the back-face of the curb should be maintained; as the traffic speed increases, distance from the bench to the curb should be increased for passenger safety and comfort;

- adhere to general ADA mobility clearances between the bench and other elements at the bus stop;

- bench should not be placed on the wheelchair landing pad; and,

- additional waiting room near the bench should be provided at bench-only stops to encourage passengers to wait at the stop itself.

The authors also include an illustration of a conceptual bench and waiting pad design.

In addition to benches, the authors discuss route information, vending machines, bicycle storage facilities, and garbage receptacles as amenities, and provide illustrations or photographs of optimal design and placement. Telephones are also classified as amenities at bus stops and customers often consider them security enhancements. The authors note, however, that telephones may contribute to illegal or unintended activities at the bus stop, such as drug dealing or loitering. The presence of others at a bus stop who are not waiting for a bus may discourage use of that bus stop or the transit system in general. The authors recommend that agencies consider the potential consequences prior to the installation of telephones at bus stops. Further, they suggest the following guidelines when locating a telephone at or near a bus stop:

- the telephone and the bus stop waiting area should be separated by distance when possible;

- general ADA site circulation guidelines should be followed; 
- the number of the telephone should be removed; and,

- the telephone should be restricted to outbound calls.

Lighting is one of the most frequently cited factors related to the perception and enhancement of safety and security at bus stops. The authors contend that good lighting has a positive effect on passenger comfort and security and that poor lighting may contribute to use of the bus stop by non-bus patrons, particularly after service hours. Although illumination requirements are generally under the purview of individual transit agencies, the authors recommend lighting that provides between two and five footcandles.

In addition to the benefits lighting may add to a bus stop, it may also add cost. As previously mentioned, the authors recommend locating bus stops near existing street lights when possible as a cost-effective means of lighting the stop. They note that when coordinating shelters or bench locations with existing lights, minimum ADA clearance guidelines for wheelchairs should be followed. In addition to cost, the availability of electrical power influences the decision of lighting a bus stop. The authors note that direct lighting is often expensive and difficult at more remote bus stop locations. They recommend the fixtures be vandal-proof and easy to maintain, such as the avoidance of exposed bulbs or elements that can be tampered with or destroyed.

Although specifics were discussed in topical sections, the authors provide the following guidelines in direct reference to passenger security:

- bus stop shelters should be constructed of materials allowing for clear, unobstructed visibility of and to the patrons inside;

- stops should be located at highly visible sites that permit bus and other drivers to see the bus stop clearly;

- avoid landscaping that grows to heights that would reduce visibility into and out of the bus stop area; particularly, evergreen trees create a visual barrier and should be avoided; low-growing shrubbery and ground cover and deciduous shade trees are recommended; 
- when possible, bus stops should be coordinated with existing street lighting to improve visibility; and,

- stops should be located next to existing land uses to enhance surveillance of the bus stop.

The authors also include a comparative table of the advantages and disadvantages of those amenities discussed in the report. They conclude with a brief discussion of the materials used in the construction of bus stops and bus stop amenities. A table of the advantages and disadvantages of wood, metal, concrete, plastic, and glass is also provided.

Nsour (1999) conducted sight investigations of 12 bus stops in California to assess the safety and security of their surrounding environments and the paths leading to and from the stops. The author notes few factors contributing to problems of safety and security at these particular stops. Some stops were located far from crosswalks, resulting in some level of jaywalking. Nsour also found there was little room for vehicles to go around stopped buses, and because drivers would either have to stop completely or quickly go around the buses, it created a potential hazard for accidents. He calls for the location of bus stops in proper relation to crosswalks and being in a safe environment.

Although providing no discussion of the implications, the author states that at some bus stops there were people "hanging around in very suspicious ways" (9). $\mathrm{He}$ asserts, however, that crime levels within any transit environment are essentially a reflection of the crime levels of the area in which the service operates. In his survey of 25 transit agencies, the author notes this was recognized by some of the agencies. Nsour stresses the necessity of public education on the part of transit agencies regarding the relative safety and security of bus transit, particularly as compared to traveling by car. This recommendation is in response to the finding that transit non-users had a higher level of fear regarding the safety and security of public transit than did users.

The location and design of bus stops in Los Angeles have received a fair amount of study, particularly with regard to crime and environmental attributes of the area 
surrounding a bus stop. Loukaitou-Sideris (1999) first presents a general overview of bus stop crime, and contends that women, children, senior citizens, and the disabled are the most fearful and vulnerable within bus stop settings. She argues that concerns of safety and security are most prominent among inner-city residents, many of whom are dependent upon public transportation. The author surveyed 95 women and 107 men at six of ten bus stops in Los Angeles identified as "high-crime" stops. Fifty percent of these bus riders reported feeling unsafe at stops, but only one fourth reported feeling unsafe on the bus itself. Of the women who were surveyed, 59 percent reported feeling unsafe while waiting for the bus, as did 41 percent of the men.

The author declares that while there has been much discussion on countermeasures to transit crime, transit agencies have focused upon police presence and the use of security hardware in transit vehicles rather than the environmental design attributes that may contribute to bus stop crime. Location and design are critical to deterring crime at bus stops, and land uses near the stop can greatly affect its safety and security. Those land uses considered to be "negative" by Loukaitou-Sideris include:

- liquor stores;

- bars;

- seedy motels/hotels;

- check-cashing establishments;

- pawn shops;

- vacant lots/buildings; and,

- adult book stores and movie theaters.

According to the author such land uses can often contribute to crime because they encourage "antisocial behavior, concentrate lucrative targets, and attract potential criminals" (406). She recommends either not locating a stop near such establishments or at least careful monitoring of the stop.

Loukaitou-Sideris also notes that other micro-environmental features may contribute to crime levels at bus stops. Those stops in areas of general neglect 
with graffiti and litter suggest no one cares about or regulates the area. Bus stops near surface parking lots, vacant buildings, or other such empty spaces isolate people who are waiting for the bus, increasing feelings of vulnerability. Walls, bushes, tunnels, and other such features may provide hiding places for criminals, as well as areas of entrapment for victims. In contrast, stops located near well-maintained businesses with open storefronts indicate there are local stakeholders in the bus stop and enhance the visibility of waiting passengers. The author also notes the value of good lighting, visibility from passing traffic and nearby businesses, and unobstructed shelters at bus stops. Siting bus stops near negative land uses with poor maintenance and with obstructed views into and out of the stop should be avoided or modified. If these options are not costeffective, she recommends moving the bus stop to a more appropriate location, as this is a relatively simple and inexpensive solution.

According to Loukaitou-Sideris, different environmental conditions incite different types of crime. While isolated areas are typically associated with more serious crimes, crowded situations are the choice for pickpockets. To mitigate these types of crimes at bus stops, the author again recommends strategic environmental design. Widening of sidewalks and the creation of nubs serve to decrease the amount of congestion between waiting bus passengers and other pedestrians. Shelter designs with bars or other features can also separate the two groups and may be very helpful at extremely crowded times. LoukaitouSideris' final recommendation is that "nonessential structures" such as newspaper stands, signs, and poles be avoided to increase the functioning space of the sidewalk area (407). Using the same survey data, such issues are again addressed by Loukaitou-Sideris and Liggett (2000).

Continuing the argument that environmental attributes contribute to bus stop crime, the second phase of this research is presented by Loukaitou-Sideris et al. (2001). The results are also discussed in Ligget et al. (2001). In this phase researchers expanded the study to include a larger sample of high-crime as well as low-crime stops in Los Angeles, and incorporated quantitative methodologies in assessing the effects of the built environment on bus stop crime. The bus stops were analyzed at the intersection level. Although the crime data were based upon those crimes reported at bus stops, the locations were recorded by 
transit police according to the street address or closest intersection. The authors note this made it impossible to determine at which stop a crime occurred in areas with multiple stops at an intersection, hence the analysis was performed at the intersection level.

Loukaitou-Sideris et al. present a matrix of the crime data for each intersection used and the environmental attributes considered in their analysis. The following characteristics were examined with regard to the area surrounding the bus stop/intersection:

- alley;

- mid-block connections;

- multifamily residential;

- parking structure;

- surface parking lot;

- liquor stores;

- check cashing;

- vacant lot;

- vacant building;

- run-down building;

- graffiti/litter;

- public telephones;

- no visibility; and,

- no bus shelter.

The authors' analysis reveals that particular urban factors and bus stop characteristics may contribute to the impact of crime at a stop. High-crime bus stops were found to have more negative environmental attributes than did their low-crime counterparts. Alleys, mid-block passages, multifamily housing, "undesirable" businesses such as liquor stores and check-cashing establishments, vacant buildings, graffiti, and litter were identified as elements that correlate with bus stop crime. Furthermore, the proximity of such establishments, most notably liquor stores, were found to increase the incidence of crime at the stop. Positive characteristics of note were good visibility and bus 
shelters, and lower crime areas were those with higher rates of vehicular traffic. Loukaitou-Sideris et al. conclude by acknowledging the early stage of the research makes it premature to suggest a causal relationship between the environmental attributes and the bus stops examined in the study.

Another study focusing on the location of bus stops and shelters in Los Angeles was prepared by Law and Taylor (2001). The researchers consider how the many objectives of advertising firms, local governments, and transit agencies combine to affect the siting of bus stop shelters. Because shelters are typically located on sidewalks, they are frequently controlled by private companies contracted through local governments. The authors contend the needs of transit agencies and their patrons are not necessarily taken into account in the decision of where to locate a bus stop shelter.

Law and Taylor propose a methodology to optimize the location of bus stop shelters. They combine stop-coded boarding data and headway data to analyze the effectiveness and equity of bus stop shelter location. They found it possible to increase the time passengers spend waiting under a shelter in Los Angeles by 2.3 to 2.4 person-years per day if bus service and patronage considerations were to be incorporated with those of the advertisers.

The authors state that the public may avoid using transit if they feel unsafe or if there is no protection from the elements. Shelters that are well designed and maintained can greatly enhance the perception of safety and increase transit use. The authors argue that an equitable method of placing bus stop shelters would concern itself with the stop's level of use by older people and the disabled and the physical abilities of these users. Further, all bus riders should receive consideration so that the proportion of time riders spend waiting at a shelter is maximized compared to the wait time of all passengers. This statement is tempered with the note that there are some cases in which all bus riders should not be treated equally. Regardless of the average number of waiting passengers at stops, a shelter may be warranted if the stop is used primarily by seniors and/or the disabled. Law and Taylor suggest several placement policies to address such concerns: a fixed number of shelters installed near hospitals and/or senior centers; permitting a small number of direct shelter requests from 
community members; or weighing boardings by older or disabled passengers more heavily in calculating bus stop use.

The location and design of bus stops have also been addressed by the Grand Junction/Mesa County Metropolitan Planning Organization through the development of standards and guidelines for stops within the Grand Valley Transit (Colorado) service area. Improvements to the pedestrian systems connecting to transit stops are considered to be de facto improvements to transit stops, thereby making the transit system more enjoyable as well as safer for passengers to use.

The brief MPO document considers stop location and types, noting there is no single standard that can be recommended for all locations. Two flowcharts are provided to assist in the determination of bus stop locations and decisions related to the type of stop. Although no mention is made regarding the safety of the specific vulnerable populations discussed here, the guidelines do address elements of a bus stop commonly mentioned by other authors:

- waiting areas including adequate space and clearance for passenger access to buses, other amenities, and connecting sidewalks;

- benches placed no closer than five feet from the curb where the posted speed limit is $35 \mathrm{MPH}$ or less; no closer than 10 feet from the curb where the posted speed limit is greater than $35 \mathrm{MPH}$; and no closer than 10 feet where there is no curb;

- shelters should be considered at any stop serving more than 40 boarding/transferring passengers per day in major commercial areas or more than 25 passengers within urban and suburban areas; any stop that is a major transfer point; and any stop located near schools, senior citizen housing facilities or community centers where concentrations of the young or older people are expected; and,

- adequate lighting enhances passenger safety.

While these design standards and guidelines were developed specifically for the Grand Valley Transit service area, they may be applicable in other areas as well. 
These guidelines are meant to balance the needs of all roadway users, including those using transit.

Arlington County, Virginia has also made advances in the development of bus stop design standards and the assessment of bus stops. The Arlington County Bus Stop Evaluation Program was developed under contract with the $\mathrm{KFH}$ Group, a private consulting firm in Bethesda, Maryland. Researchers collected information regarding the bus stop improvement programs from five transit agencies: Tri-County Metropolitan Transportation District of Oregon, Portland, Oregon; Capital Metro of Austin, Texas; PACE Suburban Bus in Arlington Heights, Illinois; Pierce Transit of Tacoma, Washington; and Chittenden County Transit Authority in Burlington, Vermont.

The recommended bus stop design standards are addressed in three parts: bus stop placement; minimum bus stop elements; and passenger amenities at stops. With regard to bus stop placement and the safety and security of vulnerable customers, the standards note general pedestrian safety and access, traffic safety, and the availability of adequate rights-of-way in compliance with ADA accessibility standards. This section also presents guidelines for stop spacing, placement in relation to intersections and roadways, curb clearance, and several other factors such as sidewalk conditions, compatibility with adjacent properties, on-street parking, and proximity to major trip generators. With regard to lighting, it is stipulated that bus stops served after dark should be illuminated at night. The light source is preferably the overhead street light, and if this is not possible the installation of adequate lighting should be considered. A table is also included in this section detailing the advantages and disadvantages of near-side, far-side, and mid-block stop locations, including recommendations as to when each type is most appropriate.

The next section presents suggested standards for the minimum characteristics of a bus stop that make it functional for bus and patron use, including those with disabilities. The landing area, pedestrian connections, signage, curbside safety and security, and newspaper boxes (as potentially inhibiting access) are briefly addressed. With regard to the landing area of the bus stop, accommodating wheelchairs is a particular concern. The dimensions, slope, surface material, 33 
and relative height to the street are all addressed from this perspective. The following is a summary of the recommendations regarding landing areas:

- dimensions-continuous, unobstructed solid area contiguous to the curb that measures at least five feet parallel to the street and at least eight feet perpendicular to the street; this is expressed in a diagram;

- slope-must be parallel to the slope of the roadway so that wheelchair lifts or ramps may be deployed effectively;

- surface material-concrete is the preferred surface; in uncurbed shoulder areas the landing area may be constructed of asphalt; and,

- height relative to the street-for pedestrian safety, the landing area should be elevated above the street level.

The researchers note that with regard to the minimum bus stop elements, new stops should not be established at locations that do not meet the minimum characteristics, and that the relocation or improvement of stops should ensure that the landing area meets or exceeds the standards.

Curbside safety and security are addressed as follows:

- location of storm drains and catch basins-can put passengers at risk of catching a foot under one when alighting or deboarding the bus;

- uneven surfaces-could cause a passenger to fall;

- slope of terrain surrounding landing area-passengers may be in danger of falling into the travel lane or an adjacent ditch or ravine;

- presence of hazardous objects-possible injury from broken street furniture or jagged edges;

- surface traction-the example is given of stone aggregate being extremely slippery for wheelchair users when it is wet;

- water accumulation areas-in addition to general hazards, can produce icy surfaces in colder climates;

- overgrown bushes-potential security concern and could create accessibility problems along sidewalks and landing areas; 
- other obstacles in the sidewalk-in addition to accessibility issues, could force pedestrians to walk into the street; and,

- area lighting-mentioned again in this section in relation to passenger safety and security as well as improving visibility for the approaching bus driver.

Shelters, advertising, benches, garbage receptacles, lighting, landscaping, and ITS features are classified as "amenities" at bus stops. With regard to shelters and benches, the researchers recommend consideration of the following:

- bus stops with ridership of at least 40 boardings per day should be priority candidates for shelters; benches may be installed independently at stops with lower daily boardings but where some amenity is desired or justified;

- strength and durability of structure and materials;

- resistance of materials to weather conditions and vandalism;

- maintenance issues;

- potential "greenhouse" effect of roof design in hot weather;

- appropriateness of design to the neighborhood;

- required dimensions of the landing area to ensure wheelchair accessibility;

- benches inside a shelter should face the street and be positioned to allow for wheelchair access and coverage within the shelter; recommended layout is at least three feet from the bench to one side of the shelter, making the bench width no more than seven feet in length; and,

- wheelchair accessibility at the bus stop, whether a bench is inside a shelter or standing independently.

Diagrams of Arlington County's standard shelter design and one exhibiting guidelines for optimal accessibility are also provided.

Although garbage receptacles have no direct bearing on customer safety and security, as noted in previously mentioned studies the appearance and surrounding area of a bus stop are important to passengers' feelings of safety and security. The standards in the Arlington County report call for the placement of garbage receptacles at stops where litter is a frequent problem. Further, they 
should be positioned to encourage their use but not block wheelchair or pedestrian access to the landing pad, bus, shelter, sidewalk, or information area. A location immediately to the left or right of a shelter is recommended, although it is noted that sidewalk conditions and right-of-way limitations may be prohibitive.

With regard to lighting, as mentioned elsewhere in KFH's report, it is most desirable to take advantage of existing street lighting, otherwise consideration must be given to the installation of lighting at stops served after dark. In addition, while landscaping may enhance the appearance of the bus stop, it should be positioned and maintained so as not to create a hazard for safety or accessibility. Plans for future ITS features such as real-time bus arrival information should be addressed through the provision of electrical hardwiring at all new stops and improvements to existing stops.

A means of assessing the existing bus stops in Arlington County was also developed in accordance with the standards discussed above, and is included in the present document as Appendix A.

Reuter and Zegeer (1998) also consider transit stops to be pedestrian areas necessitating consideration of pedestrian needs in the design and placement of stops. The authors present briefly some general guidelines for the location of farside and near-side bus stops, street furniture, wheelchair access, lighting, curb height, and signage. Again, these authors make no specific recommendations for more vulnerable populations, but several topics are applicable in this discussion.

As mentioned previously, street furniture is often considered to enhance the appearance and perception of "ownership" of bus stops. Reuter and Zegeer recommend that support poles, newspaper machines, and other permanent fixtures be minimized at the farthest end of the stop, as this is where buses usually stop. With regard to wheelchair access, the authors note that lifts on buses extend several feet from the side of the bus and therefore recommend there should be a five-foot by eight-foot landing pad at the stop so that wheelchair lifts can be deployed safely. They also state that if shelters are installed, there should be sufficient clearance between the edge of the curb and 
the shelter to allow for easy access and maneuverability of a wheelchair. Reuter and Zegeer acknowledge that lighting is a deterrent to criminal activity and that a well-lit stop assists the bus driver in observing waiting patrons and passing motorists in seeing those who are boarding and alighting the bus. Of particular concern regarding seniors and the disabled, the authors note that the most dangerous area on the vehicle itself is the step well, and a brightly lit stop will assist passengers in judging the distances and locations of curbs and steps.

Finally, Reuter and Zegeer suggest that bus stop locations should be reviewed periodically to determine whether modifications are necessary. Routine studies of pedestrian accidents should be conducted in order to identify those intersections or midblock locations where an accident may be related to bus stop design or location. They state that sites with one or more bus-related accidents should be reviewed further for possible relocation or improvements to the bus stop.

Vogel and Pettinari (2002) also contend that bus stops are areas of pedestrian concern and safety issues are often deciding factors in whether one uses transit or not. Concurring with Loukaitou-Sideris and others, these authors assert the "owned" environment provides customers with a perception and reality of personal safety and security as compared to an area that appears to be abandoned or not well-maintained. Areas of mixed and compatible land use and activity are more desirable in terms of location for bus stops because they contribute to transit use as well as personal safety and security.

Visibility is also critical in the creation of safe and secure transit environments. According to Vogel and Pettinari, crimes are typically committed in deserted areas hidden from the view of others, and those who do fall victim in visible or busy areas are usually taken to a more secluded location. Sightlines within the area of transit stops must therefore be thoughtfully designed. The authors cite columns, walls, fences, shrubbery, and level changes as potential hazards that could obstruct sightlines and the view of others or conceal an assailant. Related to visibility, lighting is also an important component of a safe and secure transit stop. Lighting should provide a clear view of peoples' faces and multiple sources of light provide even illumination, casting fewer shadows in addition to providing 
a deterrent to vandalism. However, too much or too bright lighting may create the "fish bowl effect" and actually compromise customer safety and security by not allowing the transit user to see out of a shelter but allowing others to see in the shelter. Maintenance such as replacing lights and trimming trees is essential to ensuring visibility at a bus stop.

Vogel and Pettinari refer to small fenced areas serving as transit stops as "people pens" which restrict pedestrian and transit patron mobility. They contend that feeling safe and secure is dependent on one's sense of mobility and the freedom of movement should be factored into a stop's design. Bus stops should be spacious because people are most comfortable when they are not forced to be too close physically to others waiting at the stop. Adequate space will allow someone to move to another part of the bus stop if desired and eliminate crowding.

Readability is also considered to be an important element of a safe and secure bus stop because humans feel safer and actually are safer if they know where they are, where they are going, and are able to follow a clear path to get there. According to the authors, visual cues can make the transit environment readable or confusing. An environment or design unique to a particular area or stop and clear, assessable signs can provide visual cues. However, objects or surfaces are considered to be the most important visual cues. Features such as paved pathways, street furniture, and bollards can assist patrons in getting to the stop and buffer them from potential danger.

Vogel and Pettinari consider ownership, activity and land use, visibility, mobility, and readability to be the principles of personal safety and security in relation to transit stop environments. The design of the most effective stops accounts for all of these principles. Several sketches and photographs throughout the report serve as examples of the most desirable as well as the most ineffective designs in customer safety and security.

Needle and Cobb (1997) discuss some of the crime prevention strategies undertaken by 45 transit agencies responding to a questionnaire survey. The authors found that the transit agencies use seven classes of strategies in 
attempts to deter transit crime in general, listed in descending order of their perceived effectiveness:

- uniformed officers;

- non-uniformed officers;

- employee involvement;

- education and information;

- community outreach;

- technology; and,

- architecture and design.

It is interesting to note that other literature sources reviewed for this synthesis consider architecture and particularly design to be important in crime prevention, yet they comprise the seventh category in the above list of strategies.

The core strategy of most responding agencies with police forces remained the use of random and fixed-post uniformed patrols. These efforts included directed patrols, including special foot patrols, bicycle patrol, bus boardings, and patrols addressing "special" situations or populations such as juveniles and the homeless. The Los Angeles County Metropolitan Transit Authority uses officers on foot in the "Broadway Corridor," an area served by 87 bus routes originating throughout the city. The patrols were initiated in an effort to promote neighborhood revitalization through increased business and security. With specific attention to bus stops, the Houston Metropolitan Transit Authority of Harris County (METRO) increased the number of uniformed officers on foot patrol at downtown stops. This was done in response to a request for such action from an organization representing downtown businesses.

Like Bell (1998), the authors specifically mention (CPTED) as an effective strategy in deterring crime. According to Needle and Cobb, this approach begins with the design of transit vehicles as well as bus stops. Based on the concept of a connection between crime and the built environment, as discussed by others such as Loukaitou-Sideris, Liggett et al., and Nsour, the authors contend that the manipulation of transit's physical environment can create situations and features 
that minimize the number of targets and deter criminal behavior, thereby reducing fear and the incidence of crime within in the transit system.

One example of how CPTED has proved effective is its use within Houston's METRO system. The principles of CPTED were considered in the design of new transit centers and in the improvement of existing centers and bus stop shelters. METRO police and planners observed bus stops and shelters after dark to determine their crime potential. Improvements such as increased lighting, trimming weeds and grasses around shelters, and relocating shelters away from known drug-dealing locations were implemented immediately. General maintenance and cleaning were also performed to increase the perception of safety at bus stops. METRO'S commitment to CPTED is an established practice-any architect contracted by the system must be trained in CPTED. METRO police encountered no difficulty in applying the concepts of CPTED. Although the plan's success had not been assessed quantitatively at the time of Needle and Cobb's report, it was reported that the strategy had been effective to that point. Needle and Cobb present other case studies of transit agency strategies to deter crime, but because they do not include specific reference to bus stops they are not discussed within the present review.

As previously mentioned, contemporary public transportation is no longer viewed only in terms of operation along designated routes and the picking up and dropping off of passengers. Kikuchi et al. (2001) contend that today transit is "considered as the mobility service for one's entire trip from origin to destination including the trip to/from the bus stop as well as the trip onboard" (1-1). Despite this, relatively little focus has been placed on environmental attributes surrounding stops, which include not only the street furniture located at a stop but its paths of access and egress such as street crossing facilities and walkways. According to the authors, convenient, pleasant, and safe access to and from the stop allows for transition between walking mode and transit mode. Such accessibility issues would seem to be of particular concern for populations such as senior citizens, the disabled, and women with small children.

Recognition of the importance of transit environments on the part of the Delaware Department of Transportation was the impetus behind the research 
undertaken by Kikuchi et al. Following the development of general transit stop design guidelines, the authors selected six stops along the Kirkwood Highway Corridor and assessed their condition. They then developed recommendations for bus stop improvements based upon the principles devised in the design guidelines.

Those "ideal" bus stop conditions identified by the authors include:

- convenience to passengers-transit customers are able to reach the stop with minimum effort; path should lead directly to the stop from nearby trip generators; it should be paved, with ramps or steps installed if necessary, and all features must meet ADA guidelines;

- safety to passengers-transit customers are able to reach the stop safely and free from anxiety or conflicts related to vehicular traffic; intersection design should incorporate proper channelization defining the expected path for automobiles and pedestrians; pedestrian crossings and signals should be provided whenever possible and should be clearly marked; at long crossings, a wide median or island is desirable; and sidewalks should be provided at all stop locations;

- comfort to passenger at the stop-transit customer is able to feel comfort while waiting at the stop; at a minimum, there is a concrete pad to provide proper footing conditions; benches and shelters are supplemented by trees and greenery if possible; and there is sufficient lighting for patron security and for bus drivers to see waiting customers;

- amenities-transit customer is provided with reasonable amenities, including bus schedules, adequate lighting, public telephone, and garbage receptacles;

- community value-well-designed accessibility and features of bus stops enhance livability and the value of transit in a community; if the transit stop is unsafe or shows signs of neglect the community will view the transit agency negatively and as not being serious about encouraging transit use; community support for better bus stops is important; and,

- consideration for access by people with disabilities-disabled transit customers are given consideration in all aspects related to safety, 
including street crossing time for the pedestrian signal phase, sidewalk grade, and possible hand-guiderails.

Surveys of waiting patrons were also conducted to understand better their perceptions related to bus stop accessibility. Kikuchi et al. found that the majority of respondents chose their bus stop based on its proximity to their trip origin or destination. Only 2.4 percent cited safety and bus stop conditions as a factor in bus stop choice. According to the authors this is not surprising given that stops with safe and convenient access are rare in the survey area. They also observe that the weather was "very good" during the survey period and this may have affected participant responses. When asked specifically about the safety of accessibility, 60.3 percent of respondents indicated that crossing the street to access their stop is unsafe. Kikuchi et al. consider this to be substantial and note there are no street crossing markings or signals at most stops in the survey area.

The problems and recommended improvements to the six bus stops selected for study are discussed in terms of accessibility, street crossing, and intersection. Numerous diagrams and photographs are included to illustrate the points made in the analysis of each stop. Kikuchi et al. contend that pedestrian crossing is essential to the accessibility of a bus stop, and provide an analysis of pedestrians' chances in crossing the street and the impacts of a pedestrian crossing signal on vehicular traffic. The authors also include an excerpt from the Delaware Department of Transportation's Bus Stop and Passenger Facilities Policy detailing the guidelines for Delaware Transportation Corporation (DTC). That excerpt is included in this document as Appendix B.

Those sources reviewed here appear to be in general agreement regarding the transit stop environment. The perception and the reality of safety and security at the bus stop may be determining factors for some customers in the decision to use or not to use transit or particular transit stops. Accessibility to and from the stop, the surrounding environment, and the provision of street furniture are also issues of safety and security, particularly among groups such as women-whose concern would extend to children as well-senior citizens, and those with disabilities. 
The transit stop environment is now being approached by transit agencies, local governments, transportation departments, and community groups as more than the single point of loading and unloading passengers. A more holistic perspective is being taken as the area surrounding a bus stop is increasingly recognized as a factor contributing to its safety and security. Accessibility, design, location, and maintenance of stops must be considered carefully in the planning of new stops or improvements to existing facilities. 


\section{Technologies}

Technological innovations occur at a rapid pace in the contemporary culture of electronics, security, energy, ITS, and information technologies. Many advances hold potential for the transit industry and are being used by agencies as they strive to create safe and secure transit environments for their customers. While such technologies are undoubtedly of benefit to the general transit-using public, they may be of particular relevance to populations such as senior citizens or the disabled who often have different or additional needs as compared to the general public. Technical innovations may enhance the overall quality of life for special needs populations through safer, more secure, accessible, and user-friendly bus stops.

As noted by Reed et al. and Nsour, the length of wait times can be a factor in passengers' feelings of security at the bus stop. Uncertainty in when one's bus will arrive and how long the wait time will be is often cause for fear or discomfort among waiting passengers, particularly among those such as women and seniors who generally feel more susceptible to crime. Real-time information systems are useful in providing electronic updates to passengers as to how long their wait will be. GPS-based automatic vehicle location (AVL) technology enables transit agencies to track buses en route and provide real-time schedule information using predictive software. Depending upon the configuration of the system, real-time information may be available to passengers via telephone hotlines, the internet, cellular telephones, hand-held PDAs, LED displays at the bus stop itself, or kiosks installed in traffic-heavy areas (Carter 2002).

Among others, the Denver Regional Transportation District (RTD) provides realtime arrival information to its customers via a toll-free voice-activated telephone system known as Talk-n-Ride. The RTD also currently has 52 information kiosks installed at various transit locations and major activity centers throughout the region. Kiosks will be installed at four new locations in 2003 and an additional 23 have been proposed to receive kiosks in the future. Using the information kiosks, RTD customers can check route and schedule information, view maps, get 
information on programs and services, and plan trips using the RTD Itinerary Planner.

NextBus Information Systems, Inc. provides integrative technologies supporting real-time information for the Washington Metropolitan Area Transit Authority (Metro), among others. Metrobus customers are able to access bus arrival information for stops along the Ballston-Farrugut Square Line via the internet or personal web-enabled wireless devices, as well as shelters with electronic displays at major stops and transfer points.

As with any new technology, a fair amount of public education is necessary to provide awareness and training for the new system. A full-color glossy informational insert was placed in local newspapers as a means of reaching the public. In little more than a year of operation the NextBus system has proven effective in providing passengers with real-time arrival information. Although no formal public opinion has been solicited at this point, response to the system has been quite favorable. Anecdotal information indicates that some passengers have even become dependent upon the system's capabilities of providing their bus arrival times.

While no major technical difficulties have been reported, minor human error did create problems upon the NextBus implementation. At times, some bus drivers were either keying in incorrect bus identification information or not keying in the information at all. Also, with only eight buses equipped with the NextBus technology, it is crucial that those are the buses assigned to the BallstonFarrugut Square route. The garage did at times send a non-equipped bus onto the NextBus route. Both of these issues were resolved with further training of drivers and garage personnel. 


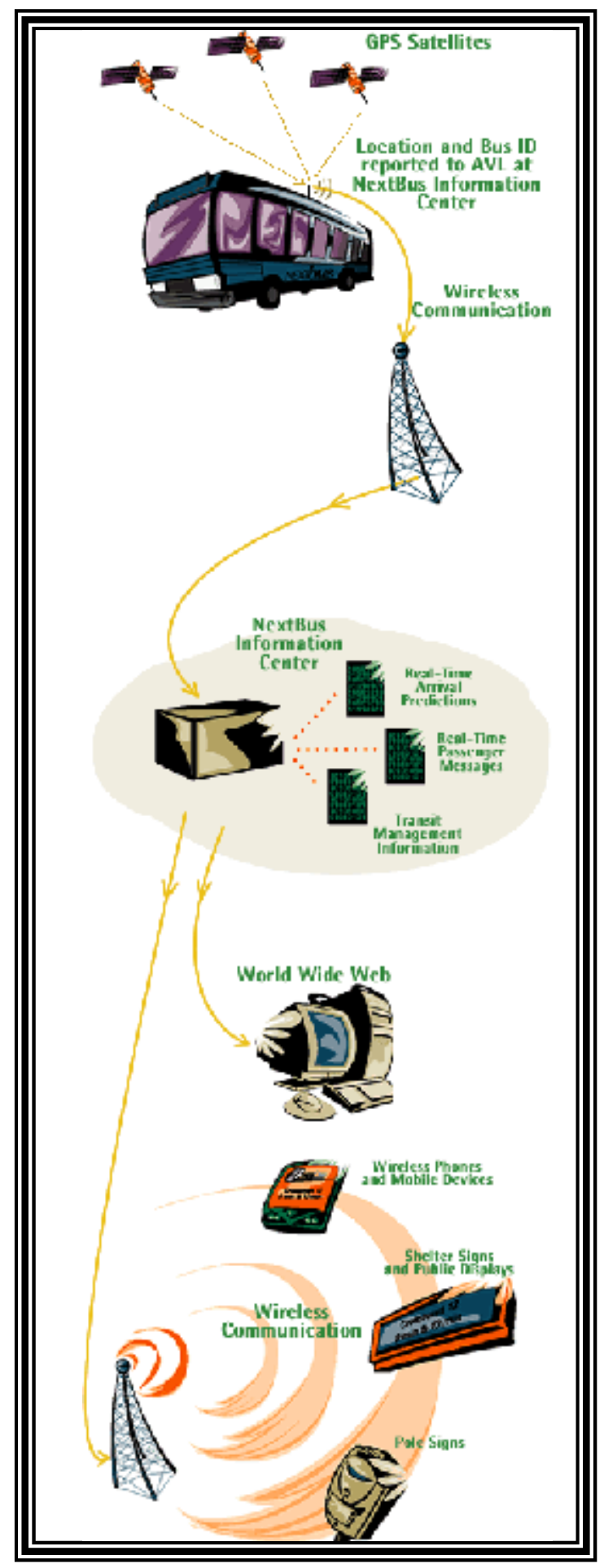

Figure 1: The Process of NextBus Technology (NextBus Information Systems, Inc. website). 
While generally considered a factor of convenience by passengers, real-time information can also be of particular value to transit customers seeking to minimize their waiting time at the bus stop. Arrival information may be accessed from the security of one's home or a well-lit public area thereby reducing the anxiety level of a long wait at the bus stop. Transit agencies have realized benefits using AVL technology as well. Carter notes that the Milwaukee County Transit System has had great success since installing AVL fleet-wide in 1995; the number of buses that were running off-schedule was reduced by 40 percent.

As previously discussed, bus stop shelters are one of the features most desired by transit customers. As the technologies in customers' hands and on the bus have advanced, so too have the technologies of the "smart" shelters. Better understanding of customer perceptions and preferences related to safety and security has been of great benefit in the design of shelters that protect from the elements while they create a safer and more secure environment for waiting bus passengers. Furthermore, materials are now being used in shelter construction that can reduce vandalism and therefore its associated costs, which benefit both the community and the transit agency.

In order to provide real-time information to passengers waiting at the stop, AVL is installed at shelters as well as on the vehicles themselves. This allows for various means of relaying information to customers at the stop or through wireless communications. Manufacturing companies provide several additional security and customer services features available for use at shelters. Daytech Manufacturing, Ltd. lists the following, which correspond with Figure 2:

- emergency button (1)-in case of danger or an emergency, passenger presses a button and a security/surveillance camera is activated to gauge if the situation is real or a prank;

- vibration/impact sensor (2)-in case of vandalism, a camera is activated by the vibration to gauge the situation;

- surveillance inside shelter (3)-camera can be activated by a monitoring station to determine the situation inside the shelter; 
- surveillance outside shelter (4)-camera can be activated by a monitoring station to determine the situation up/down the street;

- one-way voice communication (5)-monitoring station can listen and speak to shelter occupants;

- two-way voice communication (6)-monitoring station and occupants can speak to each other;

- occupancy flashing beacon (7)-alerts the bus driver that a passenger is waiting inside the shelter;

- occupancy dimmer (8)-lower light level when the shelter is unoccupied;

- outside flashing beacon (9)-speed of the beacon indicates to customers the distance of the next bus; the faster the speed the closer the bus;

- schedule and special notices/changes display (10)-a monitor displays the schedule for the day as well as any special changes;

- audio annunciation (11)-voice informs passengers of when the bus will arrive in minutes and seconds; also tells of any special information or changes; and,

- map of approaching bus (12)-graphic display on the monitor of where the bus is on the route.

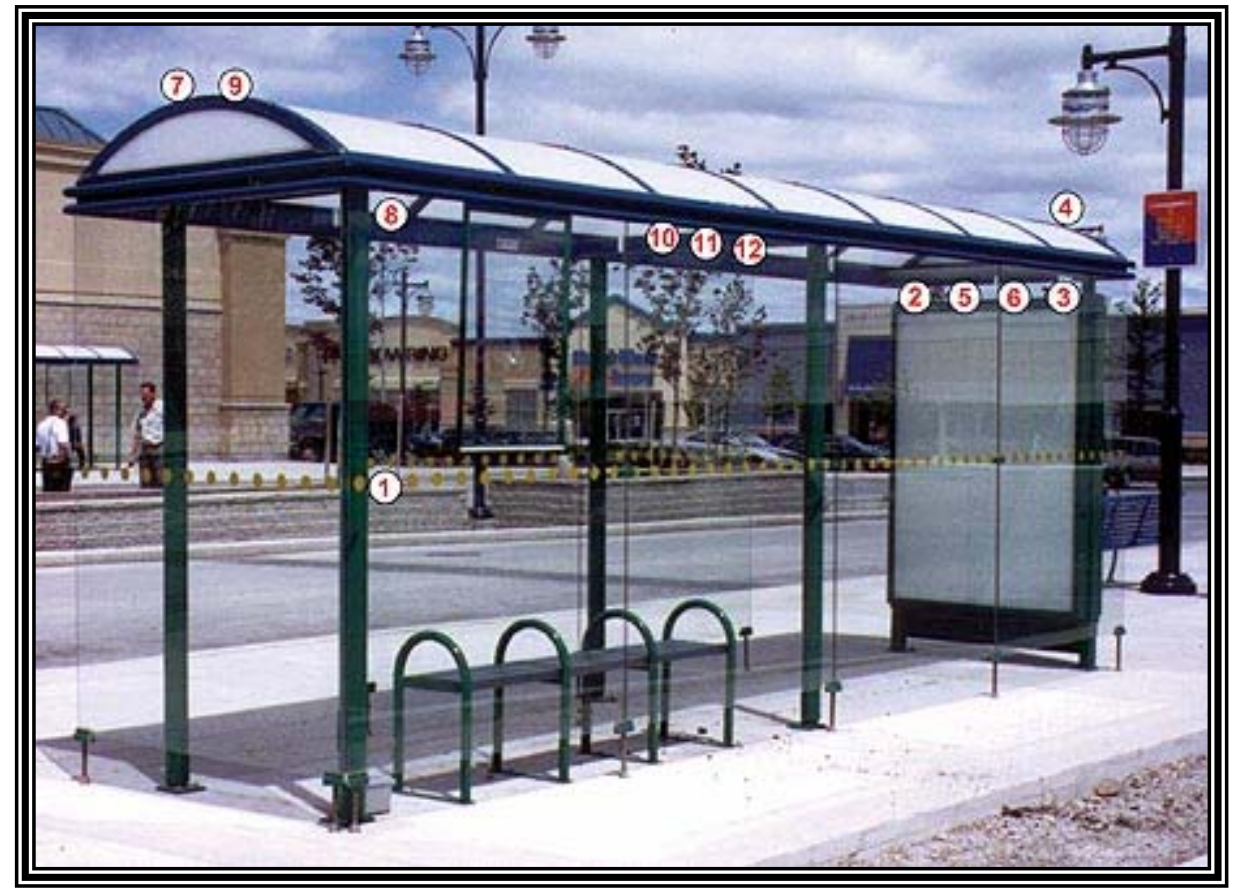

Figure 2: Features of the Smart Shelter (Daytech Manufacturing, Inc. website). 
Consideration must be given to the fact that despite the obvious benefits of the latest technologies, at this point industry-wide implementation of all of the available products or services is neither desirable nor feasible. The technological needs and capabilities of each transit system are varied and dynamic, and appropriate decisions must be made on an individual basis. It is noteworthy, however, that the various available features of most technologies can be tailored to meet client needs and budgets.

In addition to shelters and schedule/wait time information, lighting is frequently cited as an important attribute in the safety and security of bus stops. As discussed in the previous section, most authors recommend the placement of bus stops near existing streetlights to maximize both passenger safety and the cost effectiveness of providing lighting at a stop. When this is not possible, many advocate the consideration of some type of lighting at more remote stops, which is often prohibitive due to power access and cost.

Solar-powered lighting offers an environmentally-friendly and potentially costeffective means of providing light at stops in dark areas, without the need to access electrical power. OmniLight, marketed by Solar Outdoor Lighting, Inc., is a stand-alone, solar-powered light designed specifically to enhance safety and security at bus stops by providing light where electricity is not available or would be prohibitively expensive. Waiting passengers activate the light by pushing an illuminated button. The light stays on for 15 minutes, and can be reactivated by the passenger if necessary. The panel converts ultraviolet rays into electrical energy which is stored in a battery. Although adequate ultraviolet light is absorbed on cloudy days, a battery that can provide up to seven days of backup was also developed. OmniLight and other solar-powered lighting systems may provide customers more safety and security at the stop, and can also assist the bus driver in seeing that there is a waiting passenger at a stop.

In addition to those improvements realized through lighting, shelters, and better information, technologies are being developed that specifically address the needs of certain groups of vulnerable customers. Dejeammes et al. (1999) contend that bus stop design and low-floor bus equipment must be considered jointly if improvements are to be made to the horizontal and vertical gaps 
between curbs and bus floors, thereby accommodating better those passengers with reduced mobility. Within this group the authors include older people, those who have difficulty walking, parents with children in strollers, and those who use wheelchairs. The authors assessed the operating conditions of accessibility equipment on buses and drivers' capability in docking at bus stops in Grenoble, France. Based on the results of their investigation two prototype systems were developed and evaluated in an attempt to address the problems with curb and bus gaps-the GIBUS docking aid device and the VISÉE guiding system.

The GIBUS docking system is an electronic device that displays to the driver the position of the bus in relation to the curb. It consists of an ultrasonic telemeter to measures distances and is located under the body of the bus behind the front wheel; a microprocessor which could eventually be connected to the management control system; and an LED visual display that lights up progressively as the distance between the bus and the curb decreases.

The VISÉE guiding system is a bit more complex. This system guides the bus on a predefined trajectory, limiting uncertainties related to driving. It is based upon image processing and can detect "the position of the bus in the traffic lane relative to the horizontal beaconing of the carriageway (straight or broken lines) by means of an onboard video camera" (89). Using this data, the processor can calculate the ideal path of the bus, and using an electric motor it acts upon the steering system. It does not, however, take over for the driver as it is merely a device for assistance.

Dejeammes et al. conclude that the GIBUS device allowed drivers to reach the target gap distance of just less than four inches. The authors contend the GIBUS would be an effective tool for training drivers in docking. The VISÉE system provided the expected performance for both the gap between curb and bus as well as for the driver's workload, all with a high level of safety. The authors state that although the VISÉE system would certainly be more expensive than the GIBUS, it provides better performance with low discrepancy and a lower driver workload. 
In addition to addressing issues of physical mobility, technological advancements have been made in making bus stops safer for those with other forms of disabilities or concerns as well. According to Golledge et al. (1998), the accessibility and safety realized by those transit customers who are blind, developmentally impaired, foreign language speakers, or reading deficient is greatly enhanced by the use of auditory signage. This technology has the capability to provide these populations with transit information equivalent to that of standard signage and printed materials. Special needs transit users can obtain information on stop location, spatial orientation, schedules, delays, wait times, vehicle identification, and transfer points.

Golledge et al. list the following types of auditory signage:

- radio signals or signs that can operate at close or remote locations;

- inductive loops driven by amplifiers and tape players installed at specific locations;

- transponders which represent passive signs activated by a code sent to them by a person using a transmitter;

- Optical Character Readers which can include both bar-code readers or readers of standard alpha-numeric code;

- infrared signage; and,

- GPS-driven Personal Guidance Systems.

The authors focus on the infrared technology of Talking Signs as it and variants of such are the only ones of the above that have been developed for commercial use. The infrared function works similarly to a television remote control. The user hears messages through a hand-held receiver by the infrared transmission of the speech within the sign.

Golledge et al. worked with both legally blind and blindfolded sighted persons in the evaluation of Talking Signs auditory signage as compared to other travel methods typically used by the blind or those with some level of vision impairment. The authors found that in open field experiments the participants had difficulty finding stanchions and retracing learned routes, even with the use of guide dogs 
or echo location. With the use of Talking Signs, however, both groups completed the task in reasonable time and error free. In a task to evaluate the selection of the correct bus, blind participants were able to find the bus eight out of ten times when not using Talking Signs. With Talking Signs, each participant from this group was able to identify the correct bus. The blindfolded group had slightly less success, with only two of nine finding the bus when not using Talking Signs. On the first trial of using Talking Signs this improved to five of nine and in the second trial seven of the nine participants in this group identified the correct bus. Although all participants reached the correct boarding site using Talking Signs, some of the blindfolded participants did not arrive until the bus had departed.

The authors conclude that auditory signage is useful even for inexperienced users in both wayfinding and bus identification. In general the technology was considered quite favorably by members of both groups. Participants highly endorsed remote auditory signage for assistance in location, direction, orientation, bus identification, and wayfinding.

Implementation requires the installation of two Talking Signs on each bus, which the authors estimate to cost approximately $\$ 2000$ per bus. They caution, however, that this is but one aspect of such an undertaking as Talking Signs would also need to be installed at many bus stops and shelters along transit routes. Golledge et al. contend that improvements in the quality of life for the many people who need such devices more than accounts for what may be perceived as inconvenient or costly. Increased independence and the reduction of stress, anxiety, fear, and uncertainty in travel are considered to be at such a substantial level that the technology is regarded as "extremely worthwhile."

Blind Signs, Inc. has developed a far more low-tech device to assist the visually impaired in orientation and mobility. Blind Signs is a Detectable Directional Guidance System (DDGS) that uses a standardized system of raised markers that can be detected by caning or walking, but that do not interfere with other mobility devices such as wheelchairs or walkers. The markers can be mounted to any surface and form to any contour. Each configuration is approximately two feet by two feet in size. 
The system is designed to be a standardized means of providing warnings and directional indicators to those who are blind or have some form of visual impairment. A marker consisting of three yellow strips signifies a bus or other transit stop (Figure 3). This marker notifies the user that he or she is at the stop as well as where to board the vehicle because the marker may also serve as an indicator to the driver of the targeted stopping point (Figure 4). A marker with four red strips alerts users they are about to enter a crosswalk. The strips are configured so that the pedestrian is provided directional guidance and is led into the center of the crosswalk (Figure 5). Five red strips convey a stairway leading up or down. Like the marker with four strips, this marker serves as a detectable warning and provides directional guidance.

Thus far the Blind Signs system has been implemented in Eugene and Corvallis, Oregon, and the State of Oregon Disabilities Commission Access Committee has recommended installation of the system throughout the state to test its effectiveness.

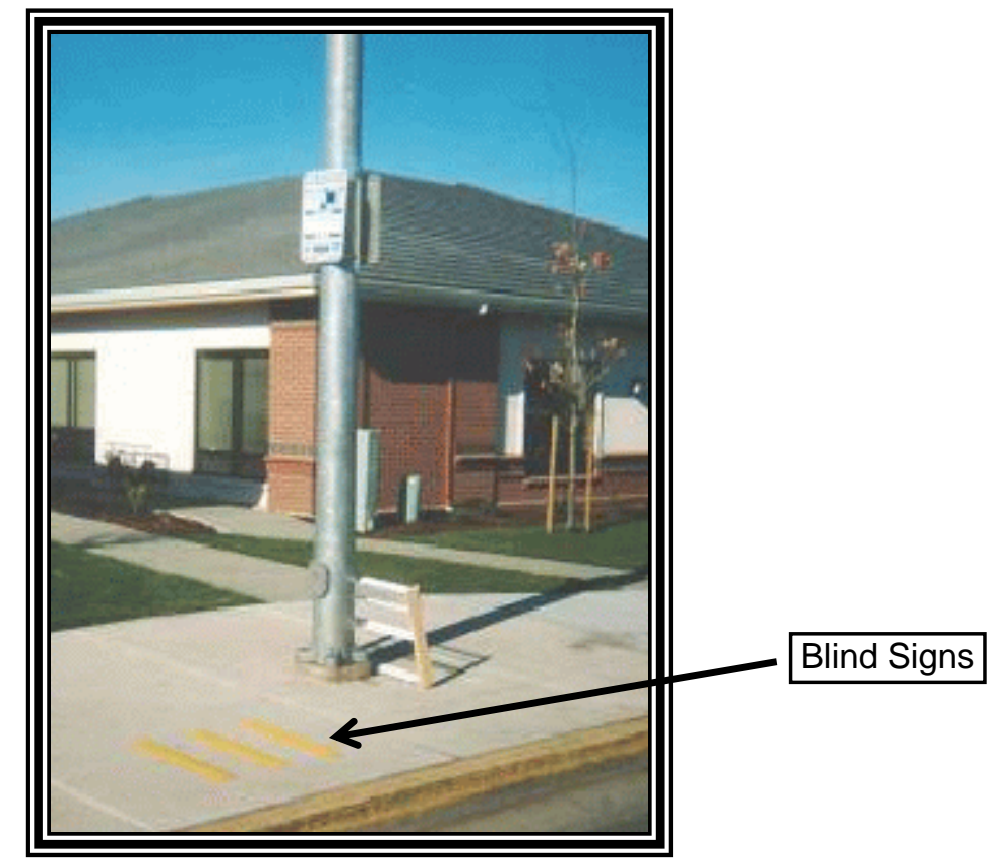

Figure 3: Three Yellow Blind Sign Strips Denoting a Bus Stop (Blind Sings, Inc. website). 


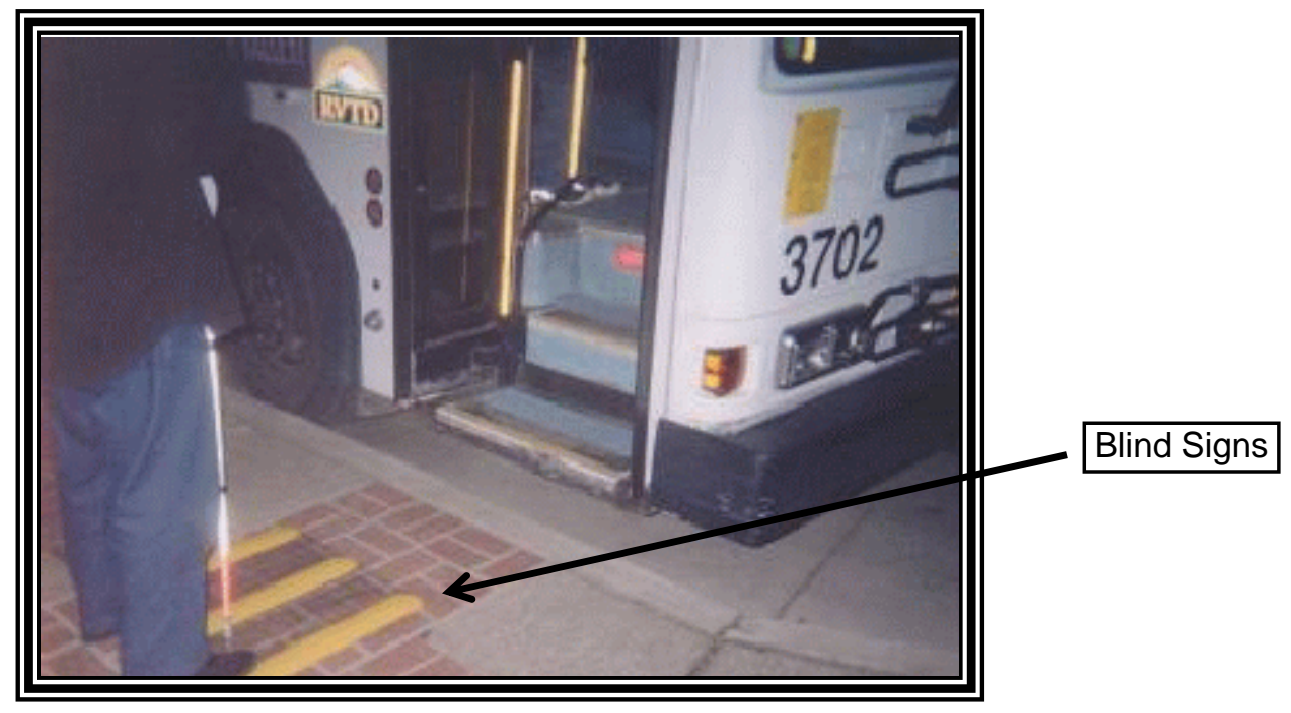

Figure 4: Three Yellow Blind Sign Strips Indicating Where to Board the Bus (Blind Signs, Inc. website).

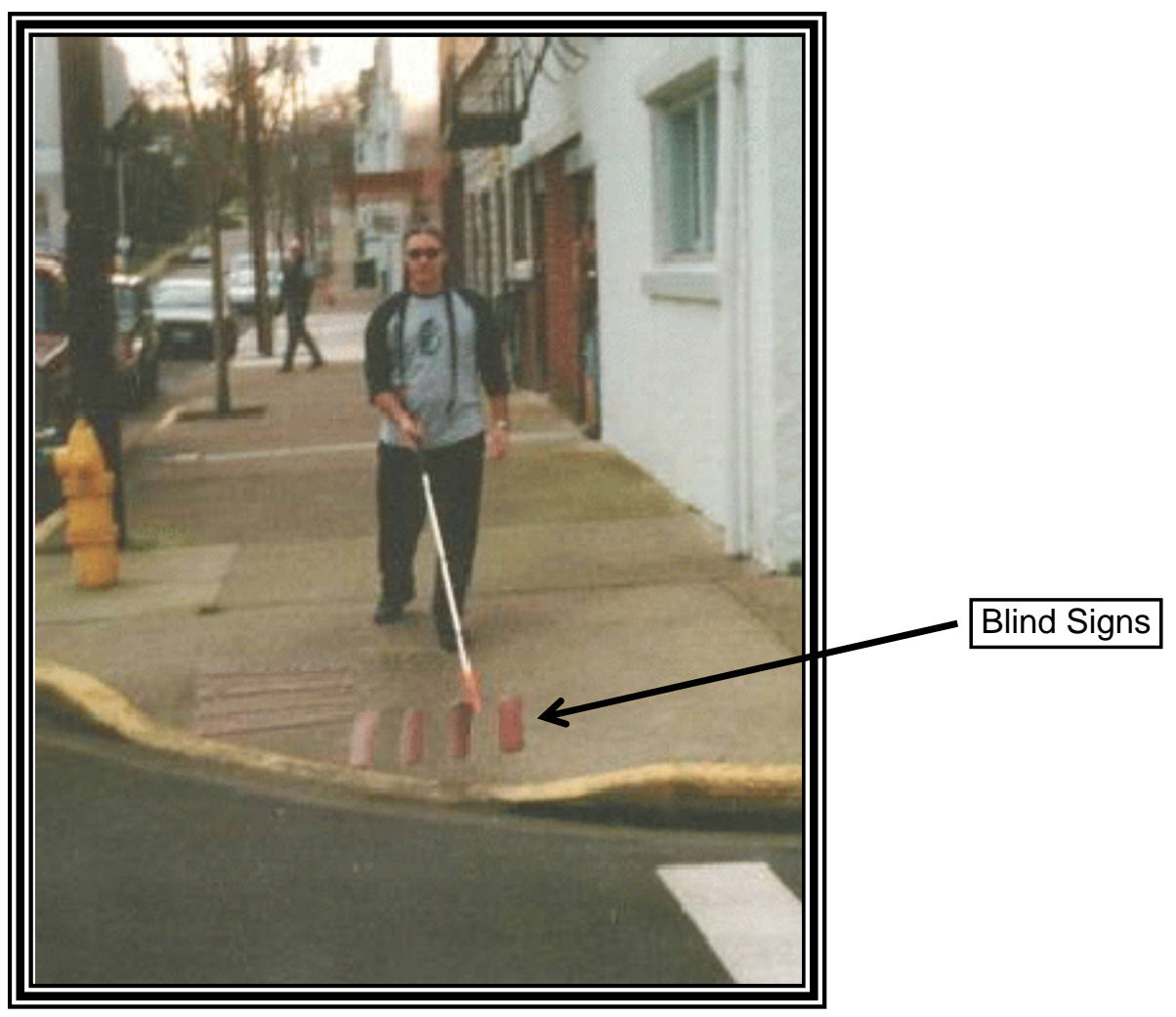

Figure 5: Four Red Blind Sign Strips Indicating Crosswalk and Direction (Blind Signs, Inc. website). 
This discussion of the technologies available in making bus stops safer and more secure is certainly not comprehensive. Technology advances at a rapid pace and the scope of this project does not permit an exhaustive study of the variety of products and services that are now available to transit agencies. Appendix C presents a brief listing of those vendors discussed here as well as others, including their website addresses. This listing is by no means comprehensive, nor does it serve as an endorsement or recommendation of any particular product or company. As good business practice, each vendor will make its product as attractive as possible, and caution must be used in the evaluation and implementation of products and services. As previously stated, the necessity and feasibility of the myriad of technical products available is an individual agency decision. 


\section{Conclusion}

A safe and secure experience at the bus stop is a fundamental expectation and right of all transit patrons. Certain populations such as women, children, senior citizens, and the disabled often have concerns that are separate from or in addition to those of the general transit-using public. These groups are often more vulnerable to problems during the trip to the bus stop as well as their wait time upon arriving. Women are generally more fearful of the crime potential in dark isolated areas or harassment in crowded situations. Such concerns for their own security typically extend to their children as well. Furthermore, mobility may be reduced for those women with small children and/or strollers, who are also loading packages. Senior citizens tend to have similar consternation regarding personal security, which is often coupled with mobility issues. For those patrons with physical disabilities or limitations, access to and from the bus stop and the deployment of vehicle lifts are essential factors. Regardless of the particular issue or its associated group, the safety and security of the bus stop may affect the decision or the ability to utilize transit. With each of these populations comprising a major market within the transit industry, the significance of safe and secure bus stops is clear.

In general, transit customers have less confident feelings related to their safety and security at bus stops than they do while actually on the transit vehicle. Understanding the needs and perceptions of transit customers is particularly important in creating safer and more secure environments for those populations that may be more vulnerable in terms of their concern or their actual safety and security. This review of the literature has found there to be several recurrent passenger concerns related to safety and security at bus stops, which include:

- shelters;

- benches;

- lighting;

- location;

- the surrounding environment; 
- design;

- maintenance and cleanliness of the stop;

- the number and type of people waiting or passing by the stop;

- wait times;

- access to and from the stop; and,

- monitoring of the stop.

As presented within this synthesis, various improvement strategies and technological innovations have been developed to address these issues and enhance the safety and security of bus stops for vulnerable customers as well as all transit passengers. The following are those enhancements or recommendations most often cited as having potential in creating safer and more secure bus stops:

- increased or improved lighting in darker areas;

- analysis of bus stop crime data;

- collaborate monitoring efforts with police;

- installation of pay telephones restricted to outbound calls or emergencyuse telephones;

- adequate signage;

- video surveillance;

- more frequent service to reduce wait times;

- relocate stops away from high crime areas or negative land uses;

- clear shelters with unobstructed views in and out;

- place benches and shelters an adequate distance away from vehicular traffic on non-slip, properly drained concrete;

- locate stops near pedestrian crosswalks and curb ramps;

- CPTED;

- locate stops near existing land uses;

- shelter materials should be resistant to the elements and vandalism;

- adherence to ADA guidelines regarding wheelchair accessibility; and,

- periodic evaluation of stops.

Several technological approaches to enhancing the safety and security at bus stops were also reviewed. These include: 
- real-time arrival information;

- smart shelters;

- solar-powered lighting;

- docking aid devices;

- guiding systems;

- auditory signage;

- directional guidance systems;

As with many applied pursuits, a collaborative approach to the improvement of bus stop safety and security may hold great potential in creating a more positive transit environment. Community involvement is increasingly recognized as a critical component of public planning, and it is now standard practice in transit planning. The vulnerable populations discussed in this document are frequent customers for transit agencies, and collaboration with representatives from these groups is imperative to meeting the needs of these important customers. Without input from stakeholders within the service community, public transportation cannot be considered truly public. In addition to those populations using and/or paying for their local transit service, other entities such as the police, environmental groups, advertisers, safety advocates, and planners all have something to contribute to the process of transportation planning. Collaboration among the various parties greatly contributes to the creation of a positive transit environment.

This concept was substantiated by the FHWA and FTA with the issuance of Public Involvement Techniques for Transportation Decision-Making in 1996. As stated in that report, people must be the focus of transportation systems and services planning. It is critical to consult with those most affected by available transportation services, or the lack thereof. Doing so identifies public values and needs, allows for the exchange of information, and fosters consensus building between transportation programs and the communities they serve. Collaboration provides transit agencies the ability to ensure that no neighborhoods or groups with special needs are overlooked. The report also notes that the involvement of those who are typically underserved by transportation is critical to successful 
decisions. Ethnic, minority, and low-income populations, and people with disabilities are cited as having lower levels of participation in the planning that is so crucial to their needs. These groups typically have more difficulty than the population at large with regard to accessing jobs, schools, recreation, and shopping. They are often unaware of the collaborative efforts to provide adequate services, and the report addresses various means of involving the public.

The many Adopt-A-Stop programs implemented throughout the country are one example of bus stop improvement at the community level, with public participation, and minimal, if any, costs to local transit agencies. Similar to the Adopt-A-Highway programs, volunteers devote a portion of time weekly, or as needed, to the maintenance and cleanup of their "adopted" bus stop. In addition to the benefits of volunteerism and community beautification, some transit agencies provide incentives to volunteers. For example, Tri-Met in Portland, Oregon awards ten bus tickets per month to each of its volunteers. This incentive has proven particularly successful among young people, who are frequent transit customers. More than 800 bus stops within Tri-Met's service area have been adopted, and litter has been reduced by 80 percent through the volunteers' efforts. With one of the concerns related to the safety and security of bus stops being cleanliness, maintenance, and the overall appearance of the stop, such improvements can greatly enhance the perception and the reality of bus stop safety. Furthermore, such efforts contribute to the concept of the "owned" environment, providing a sense of community participation in the upkeep of the transit environment.

Many factors affect the safety and security of bus stops, as well as the perception of safety and security, and several strategies and technologies have been developed to address them. It is most desirable to consider those factors affecting bus stop safety and security during the planning stages, while including the public, particularly those populations identified to be more vulnerable in terms of safety and security. Of course this is not always possible, and existing bus stops are no less deserving of enhanced safety and security. 
The bus stop is part of the overall transit environment, and is perceived as such by the public. Safety and security must be considered from a holistic perspective, accounting for the environmental attributes of the area, if the most vulnerable passengers are to feel comfortable while using transit. A better understanding of customer preferences, the contributing factors of design, and awareness of available technologies will aid in the creation of safe and secure transit environments for all transit customers. 


\section{References Cited}

Arlington County Department of Public Works

N.d. Technical Memorandum \#1: Development of Bus Stop Design Standards. Developed by KFH Group, Bethesda Maryland.

Bell, Wendy

1998 Women and Community Safety. Paper presented at the conference Safer Communities: Strategic Directions in Urban Planning, Melbourne Australia, September 10-11, 1998.

Carter, Amy

2002 GPS Keeps Transit Agencies on Track. Metro Magazine, April 2002.

Coughlin, Joseph

2001 Transportation and Older Persons: Perceptions and Preferences.

Washington, DC: American Association of Retired Persons Public Policy Institute.

Dejeammes, Maryvonne, Florent Coffin, Thierry Ladreyt, Marie-France Dessaigne, Valérie Fouet, Claude Dolivet, and René Zac

1999 Bus Stop Design and Automated Guidance for Low-Floor Buses:

Evaluation of Prototypes with Investigation of Human Factors.

Transportation Research Record 1666:85-91.

Ewing, Reid

2000 Asking Transit Users About Transit-Oriented Design. Transportation

Research Record 1735:19-24.

Federal Highway Administration / Federal Transit Administration

1996 Public Involvement Techniques for Transportation Decision-Making.

Prepared by Howard/Stein-Hudson Associates, Inc. andParsons

Brinckerhoff Quade and Douglas.

Golledge, Reginald G., James R. Marston, and C. Michael Costanzo

1998 Assistive Devices and Services for the Disabled: Auditory Signage and

the Accessible City for Blind or Vision Impaired Travelers. California

PATH Working Paper. Berkeley, CA: California PATH Program, Institute of Transportation Studies.

Grand Junction/Mesa County Metropolitan Planning Organization

N.d. Transit Design Standards and Guidelines. 
Kikuchi, Shinya, Joy Bhattacharya, Jennifer Cajthamal, Tatjana Cvetek, Daniel Feinblum, Rachel Kruger, Jonathan McNally, Dragana Miljkovic, and Aleksandar Stevanovic

2001 Development of Bus Stop Access Improvement Plans: Selected Bus Stops on the Kirkwood Highway Corridor. Newark, DE: Delaware Transportation Institute.

Law, Philip and Brian D. Taylor 2001 Shelter from the Storm: Optimizing Distribution of Bus Stop Shelters in Los Angeles. Transportation Research Record 1753:79-85.

Ligget, Robin, Anastasia Loukaitou-Sideris, and Hiroyuki Iseki 2001 Bus Stop-Environment Connection: Do Characteristics of the Built Environment Correlate with Bus Stop Crime? Transportation Research Record 1760:20-27.

Loukaitou-Sideris, Anastasia

1999 Hot Spots of Bus Stop Crime: The Importance of Environmental Attributes. Journal of the American Planning Association, 65(4):395-411.

Loukaitou-Sideris, Anastasia and Robin Liggett

2000 On Bus-Stop Crime. Access, No. 16, Spring.

Loukaitou-Sideris, Anastasia, Robin Liggett, Hiroyuki Iseki, and William Thurlow 2001 Measuring the Effects of Built Environment on Bus Stop Crime.

Environment and Planning B: Planning and Design, 28:255-280.

Lusk, Anne

2002 Bus and Bus Stop Designs Related to Perceptions of Crime.

Springfield, VA: National Technical Information Service.

Needle, Jerome A. and Renée M. Cobb

1997 Improving Transit Security. Synthesis of Transit Practice, Transit Cooperative Research Program (21). Washington, DC: National Academy Press.

Nsour, Salameh A.

1999 Safety and Security of Transit Services. Proceedings: Enhancing

Transportation Safety in the $21^{\text {st }}$ Century; ITE International Conference.

Reed, Thomas B., Richard R. Wallace, and Daniel Rodriguez 2000 Transit Passenger Perceptions of Transit-Related Crime Reduction Measures. Transportation Research Record 1731:130-141. 
Reuter, Robert C. and Charles V. Zegeer

1998 Transit Stops. In Design and Safety of Pedestrian Facilities. Pp. 104109. Institute of Transportation Engineers.

Ritter, Anita Stowell, Audrey Straight, and Ed Evans 2002 Understanding Senior Transportation: Report and Analysis of a Survey of Consumers Age 50+. Washington, DC: American Association of Retired Persons Public Policy Institute.

Stephens, Burton, Charles E. Wallace, Albert Gan, Ana Maria Elias, and Atef Ghobrial

1999 Evaluation of Transportation Safety Needs of Special Populations Using Public Transportation: Phase I-Identifying Safety Concerns. Submitted to Southeastern Transportation Center.

Texas Transportation Institute 1996 Guidelines for the Location and Design of Bus Stops. Transportation Cooperative Research Program (19). Washington, DC: National Academy Press.

Vogel, Mary and James Pettinari 2002 Personal Safety and Transit: Paths, Environments, Stops and Stations: Final Report. Minneapolis, MN: Center for Transportation Studies.

Wallace Richard R., Daniel Rodriguez, Christopher White, and Jonathan Levine 1999 Who Noticed, Who Cares? Passenger Reactions to Transit Safety Measures. Transportation Research Record 1666:133-138. 
Appendix A

Arlington County Bus Stop Assessment Form 
Bus Stop ID:

page 1

\section{ARLINGTON BUS STOP ASSESSMENT}

Name of Assessors

Date of Assessment

Time:

Weather Conditions

\section{$\underline{\text { Part I. Identification/Location }}$}

1. Is there a bus shelter? $\square$ Yes; number: $\_\square$ No

If NO, is there an exterior alternative shelter nearby (i.e. - awning, overhangs, underpass)? $\square$ Yes $\square$ No

2. Street Name

3. Nearest Cross Street

(Street Name or Landmark if mid-block)

4. Bus Route Direction:

$\square$ North Bound $\quad \square$ South Bound $\quad \square$ East Bound $\quad \square$ West Bound

5. Where is the bus stop positioned in relation to the nearest intersection?

$\square$ Nearside (Before the bus crosses the intersection) $\quad \square$ Not near an intersection

$\square$ Far Side (After the bus crosses the intersection)

6. Distance from Bus Stop to Curb of Cross Street in feet:

7. Adjacent Property Address or name of business

(Only if readily visible)

8. Adjacent Property Description:

$\begin{array}{lll}\square \text { Apartment Building } & \square \text { Library } & \square \text { Residence - detached } \\ \square \text { Church } & \square \text { Mall/Shopping Center } & \square \text { Retail Store } \\ \square \text { Day Care } & \square \text { Nursing Home } & \square \text { School } \\ \square \text { Government Building } & \square \text { Office Building } & \square \text { Supermarket } \\ \square \text { Hospital } & \square \text { Park } & \square \text { Transit station/center } \\ \square \text { Human Service Agency } & \square \text { Parking Lot } & \square \text { Vacant lot } \\ \square \text { Industrial Site/Bldg. } & \square \text { Residence - townhouse } & \square \text { Other }\end{array}$

9. Distance from previous bus stop (in miles) : 
Bus Stop ID:

page 2

\section{Part II. Pedestrian Access Features}

\section{A. Landing Area Assessment}

1. Is there a landing area at least 5 feet wide and 8 feet deep adjacent to the curb/street?

$\square$ Yes $\square$ No

2. For ART stops ONLY: Is the landing area at least 25 feet wide and 8 feet deep?
Yes
No

3. Where is the landing area positioned in relation to the curb/street?

\begin{tabular}{lll}
$\square$ Sidewalk & $\square$ Shoulder & $\square$ Curb Bulb \\
$\square$ Off-Road/No sidewalk & $\square$ Other \\
\hline
\end{tabular}

4. What is the material of the landing area?

\begin{tabular}{|c|c|c|c|}
\hline$\square$ Concrete & $\square$ Gravel & $\square$ Dirt & $\square$ Brick Pavers \\
\hline$\square$ Asphalt & $\square$ Grass & $\square$ Other & \\
\hline
\end{tabular}

5. What is the elevation level of the landing area?

$\square$ At Street Level $\quad \square$ On Curb (above street level)

6. Are there problems with the landing area surface?

$\square$ Yes $\quad \square$ No

If YES, check all that apply, and rank resulting hazard potential

$\square$ Uneven

$\square$ Slopes Up from the Street B

$\checkmark$ Slopes Down from the Street

$\square$ Requires stepping over catch basin

Other

$\begin{array}{lll}\text { Not } & \text { potentially } & \text { definitely } \\ \text { hazardous } & \text { hazardous } & \text { hazardous }\end{array}$

7. Are there any obstacles that would limit the mobility of a wheelchair? $\quad \square$ Yes $\quad \square$ No If Yes, describe obstruction:

8. Additional landing area comments:

9. Landing area recommendations:

$\square$ widen sidewalk to expand landing area to $5 \times 8$

move object to improve accessibility:

$\square$ make the following repairs:

$\square$ install curb bulb or remove on street parking:

Other: 


\section{B. Pedestrian Connections}

1. What are the primary trip generators for passengers at this stop? (Check all that apply)

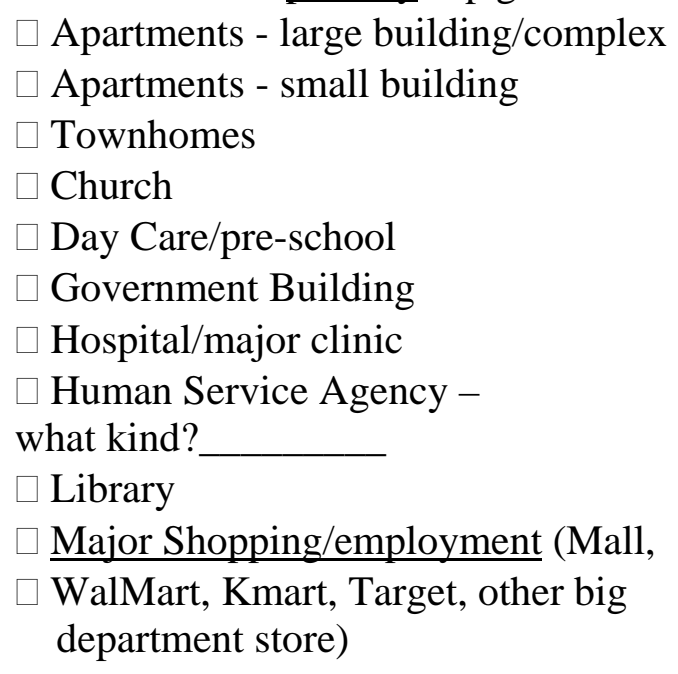

Other

Neighborhood Shopping (supermarket, drugstore, Goodwill, strip mall with basic needs shopping)

2. How wide is the sidewalk?

$$
\begin{aligned}
& \square \text { no sidewalk } \\
& \square \text { less than 3' feet }
\end{aligned}
$$$$
\square \text { 3'-5' } \quad \square \text { 5' or greater }
$$

3. Are there physical barriers that constrict the width of the sidewalk within the block on which the bus stop is located? $\quad \square$ Yes $\quad \square$ No If YES, what is the narrowest useable width: $\square$ less than 3' feet $\square$ 3' or greater

4. Does the landing pad connect to the sidewalk? $\square$ Yes $\quad \square$ No If YES, what does the sidewalk connect to:

$\square$ One of the above trip generators

$\square$ The Nearest Intersection

5. Where is the nearest street crossing opportunity?

$\square$ The nearest intersection $\quad \square$ Mid-block crosswalk

6. What pedestrian amenities are at the nearest intersection (or other crossing opportunity)?

$\square$ Curb Cuts All Corners/both

Curb Cuts At Some Corners/one side

$\checkmark$ Pedestrian crossing signal
Visible crosswalk

Traffic Light

Other:

7. Is there a bus stop across the street? $\square$ Yes $\quad \square$ No

8. Are there connections to other transportation services at this bus stop? (Check all that apply)

$\square$ Metrorail

$\square$ Commuter Rail $\square$ Greyhound

$\square$ Other 
10. Pedestrian connections recommendations:

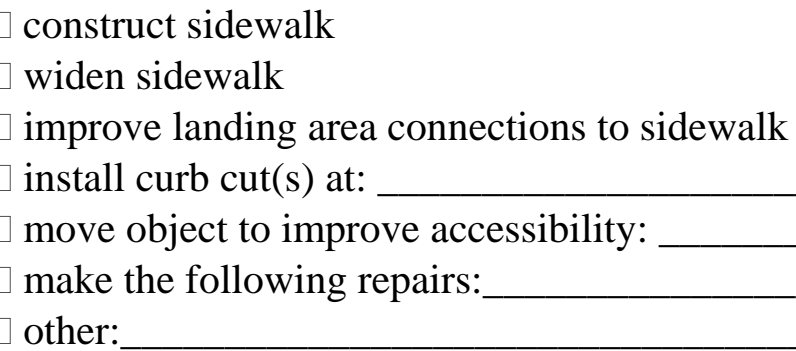

\section{Part III. Passenger Comfort Amenities}

\section{A. Shelter Assessment B move to Section B if there is no shelter.}

1. What is the orientation of the bus shelter in relation to the street?
$\square$ Facing Towards the Street
$\square$ Facing On-Coming Traffic

2. What kind of shelter is it?

$\square$ Arlington Aluminum Bfull size

$\square$ Arlington Aluminum Bhalf size

$\square$ WMATA Brown

$\square$ Other (non-standard)

3. If non-standard shelter, what are the approx. dimensions (width, height and depth in feet) of the interior standing area?

$\square$ Width

4. Does the shelter have a front center panel (i.e. two openings)?

5. Could a person in a wheelchair maneuver into the shelter?

6. Could a person in a wheelchair fit completely under the shelter?

7. What is the distance of the shelter from the curb in feet?
$\square 0$ - 2'
$\square 2^{\prime}-4^{\prime}$
$\square 4^{\prime}-6^{\prime}$
$\square 6^{\prime}-8^{\prime}$
$\square 8^{\prime}-10^{\prime}$
$\square>10^{\prime}$

8. Are there damages to the bus shelter? $\quad \square$ Yes $\quad \square$ No

If YES, check all that apply:

$\square$ Broken Panels

$\square$ Missing Panels
Graffiti

$\square$ Needs repainting
Holes in the Roof

Other 
Bus Stop ID:

page 5

9. Rank the condition of the shelter (1=poor, $5=$ =xcellent). $\begin{array}{llllll}1 & 2 & 3 & 4 & 5\end{array}$ $1=$ hazardous $B$ broken glass, unstable

$2=$ in poor shape though not hazardous

$3=$ fair B needs repainting, glass panels need thorough cleaning, protruding but not hazardous bolts

$4=$ good $B$ not perfect but no immediate repair need

$5=$ cosmetically excellent; new

10. Additional Shelter Comments:

11. Shelter recommendations:

$\square$ remove center panel

$\square$ move object to improve accessibility:

$\square$ make the following repairs:

$\square$ move shelter to improve accessibility:

$\square$ other:

\section{B. Seating Assessment}

1. Is there a bench or other seating? $\square$ Yes $\quad \square$ No

If YES please complete Section B.

If NO please move to Section C. - Trash Assessment

2. What is the type of seating available?

$\square$ Bench inside Shelter - skip to question 4.

$\square$ Freestanding Bench $\quad \square$ Other

3. If not inside shelter, what is the distance of the seating from the curb in feet?
$\square 0-2^{\prime}$
$\square 2$ ' - 4'
$\square 4^{\prime}-6^{\prime}$
6' - 8'
$8^{\prime}-10^{\prime}$
$>10^{\prime}$

4. Are there problems with the seating? $\square$ Yes $\quad \square$ No

If YES, check all that apply:

$\square$ Broken Pieces

$\square$ Not Securely Installed

$\square$ Needs Painting $\quad \square$ Graffiti

$\square$ Other

5. Rank the condition of the seating ( $1=$ =poor, $5=$ =xcellent). 1

$2 \quad 3 \quad 4 \quad 5$

$1=$ hazardous $B$ broken, someone could get hurt from normal use

$2=$ in poor shape though not hazardous

3=fair B needs repainting, needs cosmetic attention, protruding but not hazardous bolts

$4=$ good B not perfect but no immediate repair need

$5=$ cosmetically excellent; new

6. Additional Seating Comments: 
7. Seating recommendations:

$\square$ make the following repairs:

$\square$ move bench to improve accessibility:

$\square$ other:

\section{Trash Assessment}

1. Is there a trash receptacle? $\square$ Yes $\square$ No

If YES then please answer Section $C$

If NO then please move to Section D. - Newspaper Boxes

2. What is the type of installation for the trash receptacle?
$\square$ Attached to the Shelter
$\square$ Free Standing
$\square$ Garbage bag

$\square$ Bolted to Sidewalk

$\square$ Other

3. Are there problems with the trash receptacle and surrounding area? (Check all that apply)
$\square$ Trash can very Full
$\square$ Graffiti at Bus Stop
$\square$ Bus Stop Littered
$\square$ Grocery Carts Left at Stop
$\square$ Adjacent Property Littered
$\square$ Trash Can not Securely Installed
$\square$ Other

\section{Additional Comments:}

5. Trash recommendations:

$\square$ make the following repairs:

$\square$ move trash can to improve accessibility:

$\square$ install trash can due to litter problem

$\square$ other:

\section{Newspaper Boxes}

1. Are there newspaper boxes near the bus stop? $\square$ Yes; how many: $\_\_\square$ No

If YES please complete Section D.

If NO please move to Part IV. - Safety/Security Features

2. Are the newspaper boxes a barrier to sidewalk usage?

3. Are the newspaper boxes a barrier to bus access/egress?

$\begin{array}{ll}\square \text { Yes } & \square \text { No } \\ \square \text { Yes } & \square \text { No } \\ \square \text { Yes } & \square \text { No } \\ \square \text { Yes } & \square \text { No }\end{array}$

4. Are they chained to the bus stop pole, shelter, or bench?

No

6. Additional newspaper box comments: 
7. Newspaper box recommendations:

$\square$ move box(es) can to improve accessibility:

$\square$ other:

\section{Part IV. Safety/Security Features}

\section{A. Traffic and Pedestrian Safety Issues}

1. Where is the bus stop area located?

$\square$ In the Travel Lane $\quad \square$

$\square$ A Paved Shoulder $\quad \square$ In right turn only lane

$\square$ Unpaved Shoulder $\quad \square$ Off Street

$\square$ “no parking” portion of street parking lane $\quad \square$ Other

2. Is the bus stop zone designated as a no parking zone?

$\square$ Yes, indicated by: $\quad \square$ No

$\square$ one no parking sign

$\square 2$ or more no parking signs

$\square$ painted curb

$\square$ painted street

3. Are cars parked between the landing area and the bus stopping area? $\square$ Yes $\quad \square$ No

4. What is the posted speed limit? $\mathrm{MPH}$

5. What are the traffic controls at the nearest intersection for the this street?

$\square$ Traffic Signals $\quad \square$ Flashing Lights $\quad \square$ None

$\square$ Stop/Yield Sign $\quad \square$ Other

6. How many travel lanes go in the direction of the route?
$\square 1$
$\square 2$
$\square 3$
$\square 4$
Other

7. Is there a shoulder? $\quad \square$ Yes $\quad \square$ No

8. Is there on-street parking permitted just before or after the bus stop zone?
$\square$ Yes
$\square$ No If YES, length of the "no parking” area: feet

9. Are there potential traffic hazards?

Yes, check all that apply:

No

$\square$ The bus stop is just over the crest of a hill

$\square$ The bus stop is just after a curve in the road

$\square$ The bus stop is near an at-grade railroad crossing

$\square$ Waiting passengers are hidden from view of approaching bus

$\square$ A stopped bus straddles the crosswalk

$\square$ Bus stop just before crosswalk

$\square$ Other 
10. Additional traffic safety comments / recommendations:

\section{B. Lighting Assessment}

1. Is there lighting at the bus stop? $\square$ Yes, indicate type below $\quad \square$ No Street Light

$\square$ Outside Light on Adjacent Building $\quad \square$ Other

2. Additional Comments:

\section{Pay Phones}

1 . Is there a pay phone within the immediate vicinity? $\quad \square$ Yes $\quad \square$ No

2. Additional Comments:

\section{Landscaping Assessment}

1. Are there problems with the landscaping around the bus stop?

$\square$ Yes, check all that apply $\quad \square$ No

$\square$ Trees/Bushes encroaching on the landing area

$\square$ Trees/Bushes encroaching on the sidewalk

$\square$ Tree branches that would hit the bus

$\square$ Other

2. Additional Comments:

\section{Safety Recommendations:}

$\square$ improve pedestrian safety by:

$\square$ move bus stop to:

$\square$ trim trees or branches:

$\square$ other: 
Bus Stop ID:

page 9

\section{$\underline{\text { V. Information Features }}$}

1. Is there a bus stop sign? $\square$ Yes $\quad \square$ No

If YES please answer questions 1-5.

If NO please move to question 6.

2. What provider name is on the bus stop?

$\square$ WMATA Metrobus $\quad \square$ Arlington ART $\quad \square$ Other

3. How is the sign installed?

$\square$ On its own Pole $\square$ On a Building $\quad \square$ On a Utility Pole

$\square$ On a Shelter $\quad \square$ Other

4. Are bus routes indicated on the bus stop sign? $\square$ Yes $\square$ No

If yes, what routes?

5. Are there problems with the signage?

Yes $\quad \square$ No

If YES, Check all that apply

$\square$ Sign in Poor Condition

Pole in Poor Condition

$\square$ Sign Position Hazardous to Pedestrians $\quad \square$ Other

$\square$ Sign not Permanently Mounted

6. Is there route/schedule information posted?

Yes $\quad \square$ No

If YES please answer question 7.

If NO please move to question 8.

7. Where is the route/schedule information posted?

$\square$ On Pole under bus stop sign

$\square$ On its own Pole

$\square$ On a Shelter

$\square$ On a Building $\quad \square$ On a Utility Pole

$\square$ Other

8. Is there an information case? $\square$ Yes $\quad \square$ No

If YES, Check type

$\square$ square WMATA $\square$ round Arlington $\square$ other:

Are repairs needed? $\square$ no $\square$ yes:

9. Additional signage \& information comments:

10. Signage \& information recommendations:

$\square$ make the following repairs:

$\square$ other: 


\section{$\underline{\text { VI. Diagramatic Sketch }}$}

Choose the most appropriate diagram of the intersection and sketch the layout of the bus stop area and any traffic controls. On sketch, be sure to note locations of:

$\square$ bus stop sign pole
$\square$ other poles
$\square$ landing pad
$\square$ shelter
$\square$ bench
$\square$ trash can
$\square$ newspaper boxes
$\square$ anything else installed at bus stop
$\square$ sidewalks
$\square$ sidewalk barriers
$\square$ crosswalks
$\square$ curb cuts
$\square$ traffic signals/stops signs
$\square$ railroad tracks
$\square$ bus stop across the street
$\square$ north/south/east/west


Appendix B

Delaware Department of Transportation Bus Stop and Passenger Facilities Policy 


\section{Excerpt From Bus Stop and Passenger Facilities Policy}

\section{Delaware Department of Transportation}

\section{Bus Stop Design}

\section{Location}

Consistent with the flow of traffic, bus stops may be placed in three basic configurations:

- Far-side curb (placed immediately after an intersection)

- Near-side curb (placed immediately before an intersection)

- Mid-block curb (placed between intersections or along the side of a stretch of roadway)

DTC will endeavor to place all bus stops at far-side locations provided they are safe within the immediate adjacent environment. Appendix A provides descriptions and schematics of these configurations.

\section{Pedestrian Access}

Bus stop placement must have safe pedestrian access to and from the stop. Newly constructed bus stops must fulfill the federal requirements of 49 CFR Part 37, Appendix A to comply with the Americans with Disability Act (ADA) and the Architectural Accessibility Board (AAB) standards for people with disabilities (See Appendix B, Figure B-1; State of Delaware Architectural Accessibility Board Standards; and CABO/ANSI A117.1-1992). The accessible path to the bus stop should be well-drained and, when possible, placed where there are existing street lights to provide lighting and security for passengers.

The accessible pathway to the bus stop ideally has the following characteristics:

- Clear width of no less than 36", preferably 60" (the minimum width needed to allow passage of two wheelchairs simultaneously)

- Running slope of the pathway can be no greater than 1:12 (rise/run) per $\mathrm{ADA}$ and $\mathrm{AAB}$ standards

- The surface of the pathway must be firm and well-drained

- The path must have $\mathrm{ADA}$ and $\mathrm{AAB}$ compliant curb cuts at all street intersections

DTC does not itself provide physical improvements outside the immediate environment of the bus stop. It will work with appropriate organizations to ensure 
that the provision of suitable sidewalks is included in roadway improvement or land development projects to enhance pedestrian accessibility.

\section{Passenger Façilities}

The comfort, convenience, and safety of the bus stop and its approaches are key factors in attracting and retaining transit riders. Passenger facilities that are provided at each stop will be based primarily on boardings at the respective stop, as depicted in Appendix G, although special needs or circumstances may be considered. Special consideration will be given to stops that serve multiple routes and experience significant numbers of transfers.

In areas served by transit, passenger facilities will be included on highway expansion or reconstruction projects at key locations as a means of generating new ridership. During the design of the project, DTC, Preconstruction, and Planning will confer and jointly identify those stop locations having the greatest potential for expanding ridership. Passenger facilities will be provided at those identified stops when the highway is being improved.

It should be noted that physical constraints, property restrictions, and the needs of vehicle or pedestrian traffic may limit DTC's ability to install the usual facilities at some locations.

\section{Signing}

Bus stops are identified by a standard DTC bus stop. Specifications for bus stop signs and installation of same are shown in Appendix C. A number of jurisdictions within the State specify and provide their own signs; in these cases DTC will work with the appropriate officials to ensure that stops are properly signed. Signs for DTC recognized public transit services may be placed on the same post, below the DTC sign (example: Unicity in Newark).

On roads or streets where parking is permitted, bus stops should be designated "No Stopping, Standing, or Parking" zones with appropriate signing.

\section{Customer Information}

Information boards depicting routes and schedules of routes serving a stop will be provided at major stops, generally those with shelters or benches and all park and ride locations. System maps or schematics depicting the routes and available connections from the stop and other transit-related information or promotional materials may also be provided. Informational materials will be updated at each schedule change or as required.

As advanced customer information systems become available, they will be deployed at major stops or where they can be most useful to customers.

\section{Paved Passenger Waiting Areas}


All bus stops should have a paved waiting area for the safety and comfort of customers. This may be a pre-existing sidewalk or paved roadway shoulder. There should be a clear width of not less than 60 " to accommodate the turning radius of a wheelchair onto a wheelchair lift platform. Alternatively, DTC may construct concrete pads measuring at least $8 \times 8$ feet for bus stops that have consistent daily ridership. DTC will work with other DelDOT divisions and municipalities to incorporate construction of bus stop pads and/or sidewalks, as appropriate, into highway construction projects, and with private developers to include them in new construction. If a new pad is constructed, either publicly or privately, it must meet ADA and Architectural Accessibility Board Standards (see Appendix B, Figure B-1; State of Delaware Architectural Accessibility Standards; and CABO/ANSI A117.1-1992).

As ridership grows, there will be a need to install shelters, bicycle racks, or other improvements at stops. Where possible, DTC will seek to reserve space for such future improvements, including grading land beyond that required for the initial pad installation. DTC Service Development will work with relevant DelDOT offices, municipal governments, and property owners to ensure that such space is kept clear of fixed structures, utility poles, lines, ditches, and similar obstructions. Appropriate easements will be obtained for each stop location.

\section{Benches}

a. Benches are a low-cost facility to enhance the comfort of passengers at bus stops. Location criteria for installation of benches are as follows:

\begin{tabular}{|l|l|}
\hline High Transit Density & 20 or more boardings per day \\
\hline Moderate Transit Density & 10 or more boardings per day \\
\hline Low Transit Density & 5 or more boardings per day \\
\hline
\end{tabular}

Benches may also be installed in cases such as the following:

- Available space at the bus stop location will not permit installation of a shelter

- Landowner has denied the installation of a shelter

- Routes serving the stop have long intervals between buses

- Bus stops used by significant numbers of elderly or disabled persons

- Problems are experienced with passengers sitting on curbs, steps, structures or other facilities not associated with the bus stop

b. The placement of benches should be in the vicinity of shade trees or benefit from existing overhead sheltering where possible. Benches should be placed near existing streetlights, on a non-slip, properly drained 
surface, either on a sidewalk or a concrete pad within the right-of-way. On streets with high speeds or high volumes of traffic, the bench should be at least 8 ' behind the curb to ensure waiting passenger safety and comfort. The bench should be placed clear of pedestrian pathways and boarding areas, including boarding areas for wheelchair users. The bench should be constructed of vandal-proof and weather resistant material.

\section{Passenger Shelters}

a. DTC's decision to install a shelter is guided primarily by the number of passenger boardings per day, as follows:

\begin{tabular}{|l|l|}
\hline High Transit Density & 40 or more boardings per day \\
\hline Moderate Transit Density & 20 or more boardings per day \\
\hline Low Transit Density & 10 or more boardings per day \\
\hline
\end{tabular}

Additional considerations to evaluate the decision to install a shelter include:

- The number of passenger transfers at a stop

- The amount and frequency of bus service at a stop

- The number of elderly or people with disabilities utilizing the stop

- Proximity to major employment, activity, or commercial centers

- The availability of space to construct the shelter

- Ability to locate the shelter without causing a visibility hazard to traffic

b. Shelters will be of a standardized modular design to permit enlargement by adding modules, (see Appendix B for specific shelter dimensions and standards) and will be constructed of anodized aluminum frames and tempered glass or polycarbonate glazing. Components will be interchangeable for replacement in case of damage or vandalism. Shelters will be at least 5 ' deep and generally $15^{\prime}$ wide. Ten feet, twenty-five feet, or other sized shelters will be used when appropriate, based on space constraints and passenger demand. Shelters will be equipped with a bench in the rear across all but one frame or approximately 5 ' to leave room for wheelchairs and general accessibility.

In some cases municipalities or businesses may desire to have customdesigned shelters to conform to historical or architectural themes. If the location warrants a shelter, DTC may enter into a partnership arrangement under which the requesting entity will fund any and all costs beyond those 
of procurement and installation of a standard DTC shelter. If a location does not warrant a shelter, the municipality or business will be responsible for the entire cost and for all maintenance beyond routine cleaning. Failure to adequately maintain the shelter may result in discontinuation of service. In all cases, the design must be approved by DTC Facilities and Safety Sections and must comply with the $\mathrm{ADA}$ and other legal requirements.

Cantilevered shelters, without side panels or supports, may be used in locations where a standard shelter would block sidewalks or pedestrian pathways.

Shelters will be cleaned and trash receptacles emptied on a weekly basis or more frequently as determined by DTC. DTC will make every reasonable effort to maintain shelters in satisfactory condition. However, it reserves the right to remove panels without replacement or to remove shelters entirely where repeated instances of vandalism or other damage or defacement occurs.

c. Shelter placement guidelines are as follows:

- Shelters should be placed parallel to the existing outer curb or edge of paved roadway in a concrete pad or paved area (may include sidewalk where present) at least 2 ' wider than the size shelter planned for installation

- There must be a clear space of a minimum of $8^{\prime}$ from the curb either in front of or adjacent to the shelter to meet $\mathrm{ADA}$ and Architectural Accessibility Board requirements

- The concrete pad must be a minimum of 8 " thick between the shelter supports and 4" elsewhere

- The shelter can be oriented to face away from the street to protect waiting passengers from snow buildup, splashing water, or wind

- Placing bus stop shelters in front of store windows or businesses should be avoided

- Shelters placed directly adjacent to a building must have a 12 " clear space between the shelter and the building to permit trash removal and cleaning of the shelter

- Service Development will prepare shelter placement site plans, then review them with Facilities and Safety, and submit them to the local governmental jurisdiction, as required, for approval

- The shelter placement will be within the existing right-of-way or an approved area by the owner if placed on private property 
d. DTC reserves the right to remove shelters where repeated instances of vandalism or other damage or defacement occur.

\section{Privately Provided Shelters}

Businesses, developers, community organizations, or other private parties may pay for and install shelters on bus routes that serve specific developments, neighborhoods, shopping malls, or employment or activity centers. The design elements of a privately provided shelter need to meet DTC, ADA, and Architectural Accessibility Board guidelines. All designs must be compatible with customer needs and operational safety considerations. Prior to installation, an agreement on ownership and maintenance must be signed between DTC and the private provider. DTC must provide final approval on the design configurations for these facilities. Privately provided shelters may consist of a thematic or artistic design that is compatible with the major design features of the surrounding buildings or neighborhoods as long as essential security, safety, and accessibility criteria are met. The agency providing the shelter may be recognized with a small plaque or sign. DTC reserves the right to discontinue service if the shelter or its maintenance fail to comply with these requirements.

\section{Trash Receptacles}

Trash receptacles typically are provided at bus stops with shelters or benches, high volume stops, major transfer points, and specific sites where littering on site at a bus stop is identified as a problem. Trash receptacles must be placed where they will not obstruct passengers boarding or alighting from the bus, deployment of wheelchair lifts, or pedestrian traffic on the sidewalk. Trash receptacles will be emptied and cleaned on a weekly basis or more frequently if required.

\section{Lighting}

It is highly desirable to place all bus stop signs, shelters, and benches in areas where lighting is or can be provided. The lighting of bus stops offers the following advantages:

- Safety and security, both real and perceived, of waiting transit passengers;

- Ability of bus drivers to clearly see the bus stop area and passengers.

Where lighting is not available, DTC may coordinate with local government to provide it for bus stop areas having night service, high ridership, or significant numbers of transfers.

Interior lighting should be provided for shelters, although it is recognized that maintenance and utilities become an ongoing operational expense. Solar-powered overhead lighting systems may be used to minimize utility costs, both at installation and throughout the life of the shelter. Lighting fixtures will be modular to facilitate installation, replacement, or removal. DTC reserves the right to remove lighting fixtures where repeated instances of vandalism or other 
damage or defacement occur.

\section{Additional Convenience Facilities}

Additional convenience facilities may be installed at highly utilized transit stops, in particular where shelters exist. This is done to increase the attractiveness and customer friendly environment of bus stops and Park and Ride lots. DTC will coordinate the installation of such facilities but does not assume any liability associated with their presence or use. Facilities to be considered will include:

- Pay phones

- Newspaper boxes

Public telephones will be placed at all park and ride locations and at major bus stops. The installation should adhere to ADA accessibility guidelines and not obstruct pedestrian circulation. Telephones may be limited to outgoing calls only outside of DTC's normal operating hours at the location. Phones provide passengers convenience to make personal or emergency calls and to have access to transit information.

The installation of vending machines and newspaper boxes will be the responsibility of private vendors. Where bus stops are located within DelDOT right-of-way, DTC will require that boxes be secured to reduce vandalism and be placed in a location that does not interfere with pedestrian traffic or wheelchair access to the shelter.

\section{Bicycle Storage Facilities}

As part of its commitment to provide a range of multi-modal transportation choices to transit customers, DTC will provide bicycle storage facilities at high volume, park and ride lots or in other appropriate locations statewide. Identification of specific sites will be based on bicycle plans developed by the Department of Transportation, local transportation planning agencies, and cycling advocacy groups. DTC will also consider installing bicycle facilities where requested by potential users. Bicycle facilities add significantly to the right-ofway and paved area required for a bus stop, so their installation must be based on a clearly identified demand. Bike and ride locations must be served by safe bicycle access routes.

Due to the escalating cost of bicycles and the high incidence of vandalism to bikes left on bike racks, bicycle lockers will be provided at sites where customer demand and the local bicycle circulation network warrant. Lockers may be rented from DTC; applicants are given a key to the locker.

\section{Back to Top}


Appendix C

\section{Vendor Listings}




\section{Real-Time Information Systems}

NextBus Information Systems, Inc.

http://www.nextbus.com/

Inova Corporation

http://www.inovatransit.com/index.htm

Orbital Sciences Corporation

http://www.orbital.com/TMS/PublicTransit/index.html

CleverDevices Ltd.

http://www.cleverdevices.com/

Adaptive Micro System, Inc.

http://www.adaptivedisplays.com/Pages/transportation.htm

\section{Shelters}

Daytech Manufacturing, Ltd.

http://www.daytechmfg.com/

Tolar Manufacturing Company

http://www3.thomasregister.com/olc/tolarmfg/

Handi-Hut, Inc.

http://www.handi-hut.com/index.html

Brasco International, Inc.

http://www.brasco.com/

Columbia Equipment Company, Inc.

http://www.columbiaequipment.com/ 


\section{Solar-Powered Lighting}

Solar Outdoor Lighting, Inc.

http://www.solarlighting.com/index.html

Carmanah Technologies, Inc.

http://www.transitlights.com/default.aspx

Design Dimensions

http://www.designdimensions.com/index.html

Startronics Solar Lighting

http://www.startronics-solar.com/index.htm

\section{Auditory Signage and Directional Systems}

Talking Signs, Inc.

http://www.talkingsigns.com/

Blind Signs, Inc.

http://www.blindsigns.com/

Digital Recorders, Inc.

http://www.talkingbus.com/index.html 